\title{
WestVirginiaUniversity
}

THE RESEARCH REPOSITORY @ WVU

Graduate Theses, Dissertations, and Problem Reports

2005

\section{Evaluation of quality control parameters for Superpave hot mix asphalt}

Thomas W. Adams

West Virginia University

Follow this and additional works at: https://researchrepository.wvu.edu/etd

\section{Recommended Citation}

Adams, Thomas W., "Evaluation of quality control parameters for Superpave hot mix asphalt" (2005). Graduate Theses, Dissertations, and Problem Reports. 4131.

https://researchrepository.wvu.edu/etd/4131

This Thesis is protected by copyright and/or related rights. It has been brought to you by the The Research Repository @ WVU with permission from the rights-holder(s). You are free to use this Thesis in any way that is permitted by the copyright and related rights legislation that applies to your use. For other uses you must obtain permission from the rights-holder(s) directly, unless additional rights are indicated by a Creative Commons license in the record and/ or on the work itself. This Thesis has been accepted for inclusion in WVU Graduate Theses, Dissertations, and Problem Reports collection by an authorized administrator of The Research Repository @ WVU. For more information, please contact researchrepository@mail.wvu.edu. 


\title{
EVALUATION OF QUALITY CONTROL PARAMETERS FOR SUPERPAVE HOT MIX ASPHALT
}

\author{
By \\ Thomas W. Adams \\ Thesis submitted to the College of Engineering and Mineral Resources \\ at West Virginia University \\ in partial fulfillment of the requirements for the degree of \\ Master of Science \\ in \\ Civil Engineering
}

John P. Zaniewski, Ph.D., Chair

Ronald W. Eck, Ph.D.

Jim French III, Ph.D.

Department of Civil and Environmental Engineering

Morgantown, West Virginia

2005

Key Words

Asphalt quality control, Monte Carlo simulation, performance specifications 


\section{Abstract \\ EVALUATION OF QUALITY CONTROL PARAMETERS FOR SUPERPAVE HOT MIX ASPHALT}

\section{Thomas W. Adams}

Quality control of Superpave hot mix asphalt has profound consequences for both the West Virginia Department of Highways (WVDOH) and the constructor who has placed the asphalt. The quality control procedure includes taking samples from the job site, and performing various tests so that certain volumetric parameters can be evaluated against a standard set of tolerances. WVDOH currently uses a statistically based quality control - quality assurance method, QC/QA.

The test methods used for the WVDOH QC/QA process are standard tests published by both the American Association of State Highway and Transportation Officials (AASHTO) and the American Society for Testing and Materials (ASTM). By policy, each of these organizations includes precision and bias statements as part of each test method. The variability associated with the testing methodology should not influence the decision to accept or reject a material in the QC/QA process.

The current QC/QA requirements used by the WVDOH for Superpave projects have not been statistically evaluated to establish the risk to the agency and constructor for either accepting an unsatisfactory material or rejecting a satisfactory material respectively. A rigorous evaluation of these risks is difficult due to the interdependence of some of the quality control parameters. However, a simulation method is available that can be used to identify these risks.

The objective of this research was to evaluate the risk levels associated with the current methods of quality control and acceptance used by the WVDOH for Superpave construction projects. Risk was defined as the probability of the WVDOH accepting a substandard product or rejecting an acceptable product.

The results of the research show that test variability is not a significant factor for quality control and quality assurance. 


\section{Acknowledgements}

I would like to express my gratitude to my advisor, Dr. John Zaniewski, for his inspiration, guidance, and support. The time spent overseeing this endeavor and his willingness to be available outside of normal working hours to allow for the completion of the research were greatly appreciated. I would like to thank Dr. Zaniewski for making me a better student and technical writer through both guidance and dedication to his work. Thank you to my defense committee, Dr. Ronald Eck and Dr. Lloyd French, for their constructive comments and review of this document.

Special thanks to my parents for your support, love, and assistance through two degrees in engineering and for always being positive about everything in my life. Also thanks to my fiancée for all her support and love during this whole process. 


\section{Table of Contents}

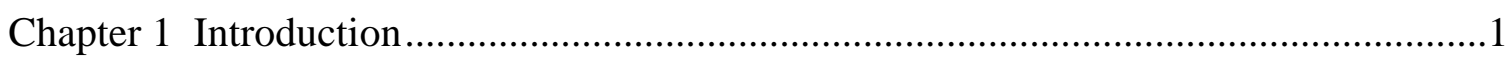

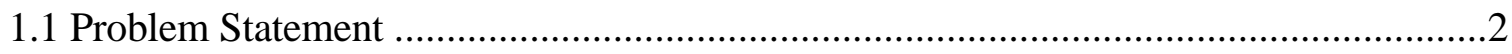

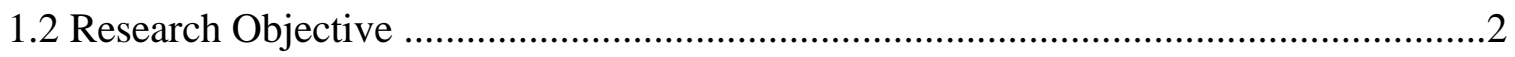

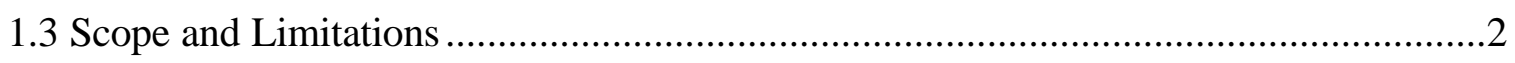

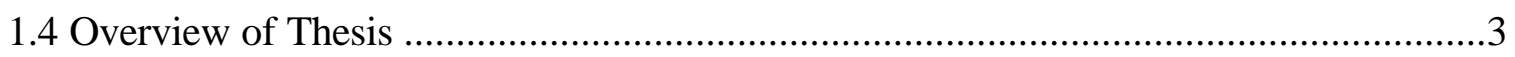

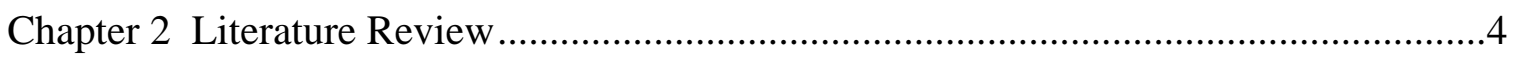

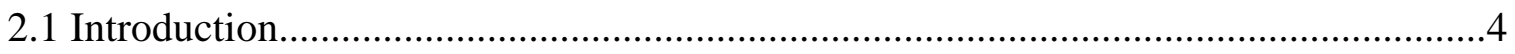

2.2 Quality Control for Superpave …………………..................................................5

2.3 Quality Assurance for Superpave ……………….............................................

2.4 Standard Test Methods For Superpave Mixes …………….......................................10

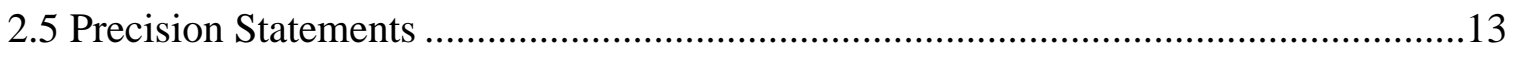

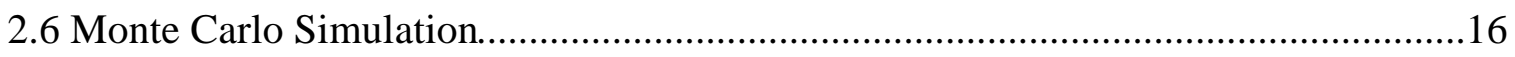

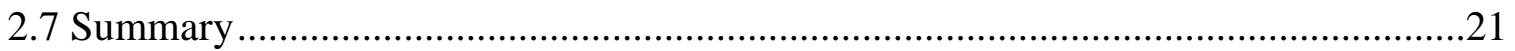

Chapter 3 Research Methodology ............................................................................22

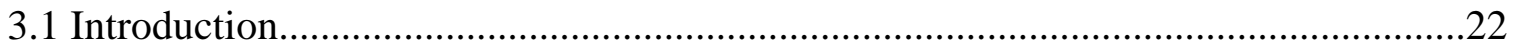

3.2 Research Approach ..........................................................................................22

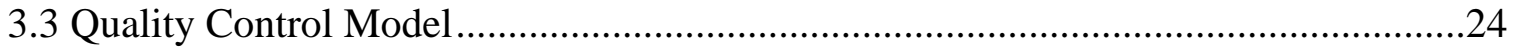

3.3.1 Standard Deviation of Sample of Means ……………............................... 27

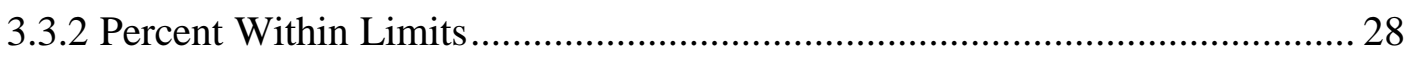

3.3.3 Aggregate Bulk Specific Gravity ............................................................ 29

3.3.4 Effects of Varying Asphalt Content ........................................................... 30

3.4 Quality Assurance Model.......................................................................................31

Chapter 4 Methodology Application and Results ...........................................................34

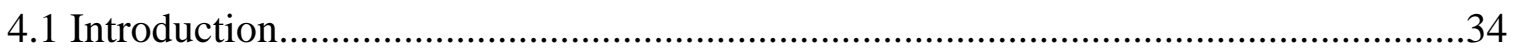

4.2 Mix Design Input and Output Values ........................................................................ 


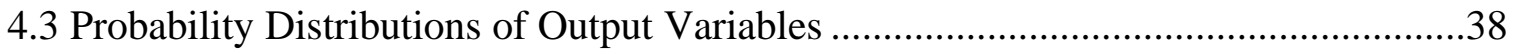

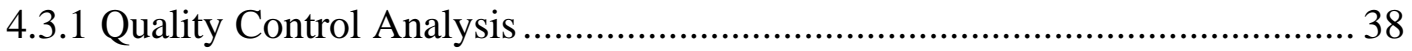

4.3.2 Effect of Varying Asphalt Content ................................................................. 42

4.3.3 Quality Assurance Analysis .......................................................................... 46

Chapter 5 Conclusions and Recommendations ..............................................................48

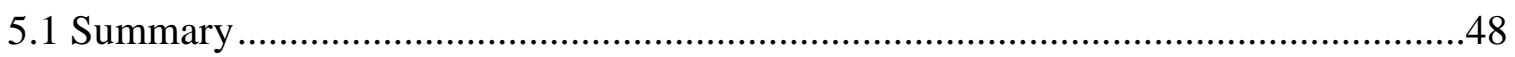

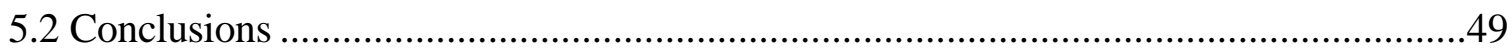

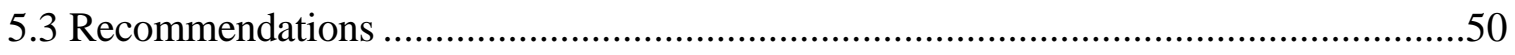

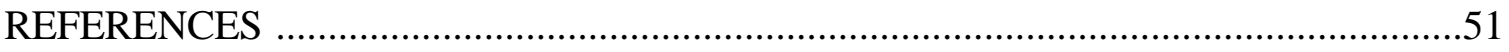

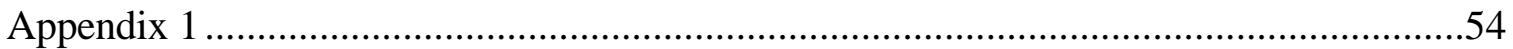

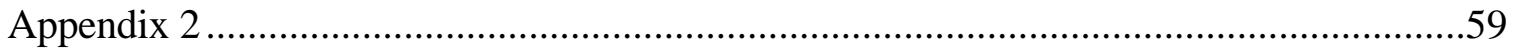




\section{List of Tables}

Table 2.1: WVDOH Quality Control Mix Property Tolerances ....................................... 6

Table 2.2: Guide for Quality Control Plans for Superpave Designed Hot-Mix Asphalt.... 7

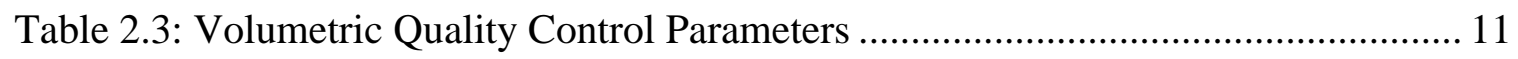

Table 2.4: AASHTO and ASTM Test Methods Affecting Quality Control..................... 12

Table 2.5: Standard Deviations for Standard Test Methods ....................................... 14

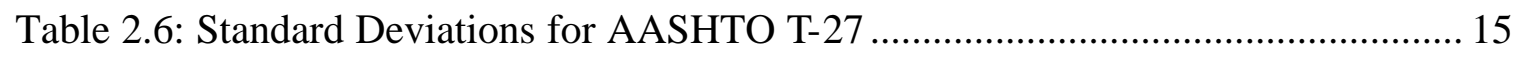

Table 2.7: Standard Deviations for 300-g and 500-g Test Samples for AASHTO T-27.. 16

Table 3.1: Mix Design Types Evaluated with MCS .................................................. 24

Table 4.1: Input Variables for Monte Carlo Simulation............................................. 35

Table 4.2: Results of Within Laboratory Data ..................................................... 36

Table 4.3: Results of Between Laboratory Data ........................................................ 37

Table 4.4: 9.5 mm mix with PG 64-22 Statistics .................................................... 40

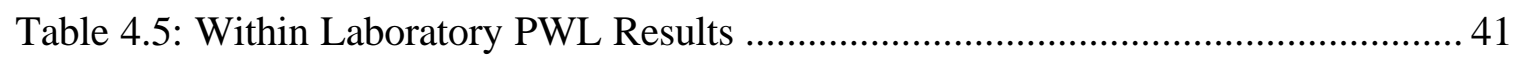

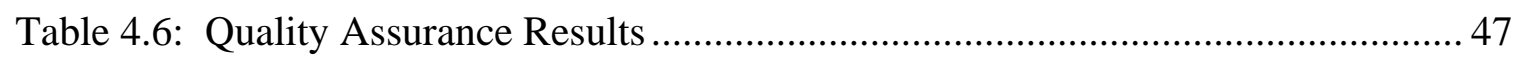

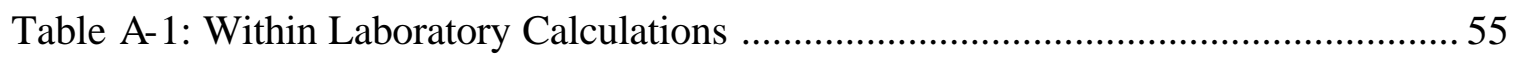




\section{List of Figures}

Figure 2.1: General Monte Carlo Simulation Approach................................................. 18

Figure 3.1: Flowchart of Quality Control Model................................................... 26

Figure 3.2: Flowchart of Quality Assurance Model .................................................. 33

Figure 4.1: Percent Within Limits with Varying Percent Binder .................................. 43 


\section{CHAPTER 1}

\section{INTRODUCTION}

Quality control of Superpave hot mix asphalt has profound consequences for both the West Virginia Division of Highways (WVDOH) and the constructor who has placed the asphalt. The quality control procedure includes taking samples from the job site, and performing various tests so that certain volumetric parameters can be evaluated against a standard set of tolerances. These tolerances are determined by the WVDOH based on mix designs prepared by the constructor and approved by the agency. WVDOH currently uses a statistically based quality control - quality assurance method, QC/QA. Under this system, the constructor has primary responsibility for the quality control. This requires that the constructor submit a quality control plan prior to the start of each project. This plan identifies the type and frequency of tests conducted during the construction. It also identifies corrective actions, if needed, in the event that the quality control parameters are outside the allowable tolerances. To ensure that the constructor is performing the quality control function in the required manner, the WVDOH performs independent quality assurance tests on a subset of the samples tested by the contractor.

The QC/QA process requires that the constructor collect samples of the asphalt concrete. A random sampling process is used to ensure the material is representative of the total amount of material placed during the project. Each sample consists of enough material to complete tests on both individual components of the mix and the mix itself. In addition, some samples are large enough to split into portions for the constructor's QC tests and the Department's QA tests.

The test methods used for the WVDOH QC/QA process are standard tests published by both the American Association of State Highway and Transportation Officials (AASHTO) and the American Society for Testing and Materials (ASTM). By policy, each of these organizations includes precision and bias statements as part of each test method. The precision statement identifies the amount of variation that is inherent to the test method. This recognizes that even if a single technician, trained and certified in 
performing the test, conducts a test using one set of equipment, that there will be differences in the results produced for replicate samples. The variability associated with the testing methodology should not influence the decision to accept or reject a material in the QC/QA process.

\subsection{PROBLEM STATEMENT}

The current QC/QA requirements used by the WVDOH for Superpave projects have not been statistically evaluated to establish the risk to the agency and constructor for either accepting an unsatisfactory material or rejecting a satisfactory material, respectively. A rigorous evaluation of these risks is difficult due to the interdependence of some of the quality control parameters. However, a simulation method is available that can be used to identify these risks.

\subsection{RESEARCH OBJECTIVE}

The objective of this research was to evaluate the risk levels associated with the current methods of quality control and acceptance used by the WVDOH for Superpave construction projects. Risk was defined as the probability of the WVDOH accepting a substandard product or rejecting an acceptable product.

\subsection{SCOPE AND LIMITATIONS}

The scope of this paper was to evaluate all Superpave mix types and asphalt binders common to West Virginia. The mixes included various combinations of $37.5 \mathrm{~mm}$, $19 \mathrm{~mm}, 12.5 \mathrm{~mm}$, and $9.5 \mathrm{~mm}$ gradations with Performance Grade binders of 64-22, and 76-22.

The limitations of this research result from the analytical approach that was used in completing the research. The standard deviations used in the calculations were obtained from the AASHTO and ASTM standard test procedure precision statements. There were no lab verifications of these standard deviations. It was assumed that the results of tests on replicate samples are normally distributed. The mean values used in all calculations were taken from mix designs developed by the constructors and approved by the WVDOH as recorded in the job mix formula submissions. These values were also not verified during this research. It was assumed that these are acceptable since they are 
used by the WVDOH in assessing quality control. The last limitation was that no fieldwork was completed and no review of particular construction jobs was performed.

All quality control procedures assume that the samples tested are representative of the population being evaluated. It was assumed that the sampling requirements in the QC/QA plans comply with this requirement. Evaluation of sampling methods was outside the scope of this research.

In recognition that small quantities of materials are more difficult to control than large quantities, the WVDOH has provisions for QC/QA that apply to small quantities. These procedures were not evaluated during this research. Only the procedures that apply to normal quantities of production were considered.

\subsection{OVERVIEW OF THESIS}

Chapter 2 presents a literature review. The current quality control specifications and procedures are expressed. The standard test methods from AASHTO and ASTM for volumetric quality control are described. These include precision and bias statements which define the expected variability of each test method. Finally, a review of published papers on evaluating asphalt mix design using Monte Carlo simulation is included.

Chapter 3 lays out the research methodology for this thesis. Monte Carlo simulation was used to evaluate the current quality control specifications of the WVDOH. The results of the simulations were presented as probability distributions for the volumetric properties used in quality control.

Chapter 4 shows the methodology application and results. The analytical method was applied to multiple variations of asphalt mix gradation types and asphalt binders to represent the common Superpave mixes used in West Virginia. The resulting probability distribution functions are analyzed and compared to the specifications used in quality control by the WVDOH.

Chapter 5 presents the conclusions and recommendations of the research. Included in this chapter are the general findings from the applied methodology results. Also stated are some recommendations of where further research could be performed to address the findings of the research. 


\section{CHAPTER 2}

\section{LITERATURE REVIEW}

\subsection{INTRODUCTION}

Specifications are used to express the quality of a product which the buyer expects from the seller. They are used as a basis for competitive bidding; as well as, being used to measure compliance to contracts during the construction phase. Statistics have been used as a basis for establishing these specification limits through means of standard test methods. Each test method has a precision and bias statement which quantifies the expected variability of the test results. The precision and bias statements quantify within laboratory and between laboratory variability. Other sources of variability include instrumental or machine variability, variability among materials, and variability from the sampling of materials. Once the statistical features of desired characteristics are known, then these statistics can be analyzed to determine the probability that material can be produced without substantial penalties or rejection of the material.

Risk analysis pertains to the buyer's and seller's potential "risk" of buying a product of unacceptable quality or selling an acceptable product that is rejected on the basis of the set specifications. Risk analysis is typically based on Operating Characteristic Curves (OC) which is explained in AASHTO Standard Recommended Practice for Acceptance Sampling Plans for Highway Construction, Designation: R 9. Operational Characteristic Curves establish an acceptable quality level (AQL) and a rejectable quality level (RQL). Using the AQL and RQL, a curve is plotted using either $z$-values for normal distributions or t-values for non-central t-distributions. "The OC curve is a graphical method of representing the capabilities of a statistically based specification for all quality levels within the zone being considered." (AASHTO, 2000) This method has been used as a method of risk analysis; however, Operating Characteristic Curves have their limitations. The construction of OC curves can only be used for characteristics that are independent of each other. For instance, asphalt content and layer thickness would be 
independent of each other and separate OC curves could be drawn for each. However, air voids and voids in mineral aggregate (VMA) are interdependent qualities since air voids are used in the calculation of VMA, and so the development of OC curves as described by AASHTO R 9 is not appropriate (Newcomb, and Epps, 2001a).

\subsection{QUALITY CONTROL FOR SUPERPAVE}

The Superior Performing Asphalt Pavement (Superpave) mix design method was developed as an effort to create performance-based tests and specifications for asphalt binders and Hot Mix Asphalt mixes. In 1987, a five-year Strategic Highway Research Program (SHRP) was started. Within SHRP, \$50 million was allocated for research to develop Superpave (Roberts, et al, 1996). Quality control methods for pavements constructed with Superpave designed mixes were not developed during the SHRP research. However, the National Cooperative Highway Research Program, NCHRP, sponsored a project to develop a generic QC/QA methodology for pavements constructed with Superpave mixes (Cominsky, et al, 1998). The recommendations of this research, along with current practices for mixes designed with the Marshall method, were considered for the development of the QC/QA system for the WVDOH.

In order for any QC/QA system to be effective, results from testing samples must be reliable and represent the properties of the "population" of material being evaluated. There are two essential requirements for obtaining reliable tests, the quality of the sampling and the quality of the testing. In each case, the results are dependent on the ability of the technicians. On a nationwide basis, as of July 2000, technicians' qualifications must be verified through certification (Decker, 2000). The WVDOH was an early adopter of QC/QA specifications and all technicians with responsibility for taking or testing samples must be certified by the State. In addition to the ability of the technicians, reliable test results require that a well-designed test method be followed using equipment that is properly calibrated. The WVDOH relies primarily on ASTM and AASHTO test methods for the evaluation of all parameters required for Superpave mix design and QC/QA. The AASHTO Materials Reference Laboratory, AMRL, must certify each laboratory. In addition, laboratories are periodically certified through inspections by the state. 
Initially, the WVDOH QC/QA specifications for Superpave mix designs require constructors to test and demonstrate that their material meets the specification limits for:

Asphalt Content, $\mathrm{P}_{\mathrm{b}}$

Voids in Total Mix, VTM

Voids in Mineral Aggregate, VMA

Voids Filled with Asphalt, VFA, and

Dust to Effective Binder, D/B.

Specification limits of the above characteristics are presented in Table 2.1 (Material Procedure 401.02.29). All test results, with the exception of VFA, are recorded to one tenth percent. VFA is recorded as a whole percent. The WVDOH subsequently dropped the VFA requirement from the QC/QA specifications (Epperly, 2003).

Table 2.1: WVDOH Quality Control Mix Property Tolerances

\begin{tabular}{|l|c|}
\hline \multicolumn{1}{|c|}{ Property } & Production Tolerances \\
\hline Asphalt Content (\%) & Verified JMF $\pm 0.4 \%$ \\
\hline Air Voids (\%) & $4.0 \pm 1.2 \%$ \\
\hline $\begin{array}{l}\text { Voids in Mineral } \\
\text { Aggregate (VMA) } \%\end{array}$ & $\begin{array}{r}\text { Verified JMF } \pm 1.0 \% \text { with a minimum of } 0.5 \% \\
\text { below the minimum design criteria }\end{array}$ \\
\hline $\begin{array}{l}\text { Voids Filled With } \\
\text { Asphalt (VFA) } \%\end{array}$ & Design Criteria $\pm 2 \%$ \\
\hline
\end{tabular}

Since these properties are dependent upon a combination of aggregates and asphalt cement, the other factors that could change the quality of the Hot Mix Asphalt (HMA) also need to be checked for quality control. For instance, temperature, moisture, and fractured faces must also be checked. A complete list of the properties checked by the WVDOH is provided in Table 2.2 (Material Procedure 401.03.50). Table 2.2 shows the test or action being checked, the frequency with which it is checked, the standard test method used, and the method of documenting the results. 
Table 2.2: Guide for Quality Control Plans for Superpave Designed Hot-Mix Asphalt

GUIDE FOR QUALITY CONTROL PLANS FOR SUPERPAVE DESIGNED HOT-MIX ASPHALT

\begin{tabular}{|c|c|c|c|}
\hline TEST OR ACTION & FREQUENCY & TEST METHOD & $\begin{array}{c}\text { METHOD OF } \\
\text { DOCUMENTATION }\end{array}$ \\
\hline Calculating mixing time & $\begin{array}{l}\text { Plant setup and when } \\
\text { paddle pitch or dam } \\
\text { gate changed }\end{array}$ & & $\begin{array}{l}\text { Plant Inspection Form } \\
\text { and Diary }\end{array}$ \\
\hline $\begin{array}{l}\text { Ross Count (degree of } \\
\text { coating) }\end{array}$ & $\begin{array}{l}\text { Only if mixing time is } \\
\text { less than } 45 \text { seconds }\end{array}$ & AASHTO T195 & Diary \\
\hline $\begin{array}{l}\text { Coarse aggregate face } \\
\text { fracture (Gravel only) }\end{array}$ & $\begin{array}{l}\text { One test before start } \\
\text { of operation Every } \\
10,000 \text { ton }(9,000 \\
\text { Mg) thereafter }\end{array}$ & ASTM D5821 & T302 \\
\hline $\begin{array}{l}\text { Complete mix face fracture } \\
\text { (When using gravel) }\end{array}$ & One per week & ASTM D5821 & T302 \\
\hline $\begin{array}{l}\text { Check moisture content of } \\
\text { aggregate }\end{array}$ & Plant setup and daily & & Diary \\
\hline Temperature check & $\begin{array}{l}\text { Minimum of one } \\
\text { check of mix per hour } \\
\text { at plant }\end{array}$ & & $\begin{array}{l}\text { Plant Control Chart } \\
\text { and Diary }\end{array}$ \\
\hline Gyratory Compaction & \multirow{6}{*}{$\begin{array}{l}\text { One test for } \\
\text { production periods of } \\
\text { sixhours or less. } \\
\text { One test for each half } \\
\text { day for production } \\
\text { periods of greater } \\
\text { than six hours. When } \\
\text { production exceeds } \\
\text { twelve hours a third } \\
\text { sample shall be } \\
\text { tested. }\end{array}$} & AASHTO TP4 & T419 \\
\hline Aggregate Gradation & & AASHTO T30 & T417 and T425 \\
\hline Asphalt Content & & $\begin{array}{l}\text { AASHTO T308 } \\
\text { (Method A) }\end{array}$ & $\begin{array}{l}\text { T417 and Control } \\
\text { Charts }\end{array}$ \\
\hline Percent Air Voids & & $\begin{array}{l}\text { AASHTO T166, T209, } \\
\text { and T269 }\end{array}$ & \multirow{3}{*}{$\begin{array}{l}\text { T419 and Control } \\
\text { Charts }\end{array}$} \\
\hline $\begin{array}{l}\text { Percent Voids in Mineral } \\
\text { Aggregate (VMA) }\end{array}$ & & AASHTO PP-28 & \\
\hline $\begin{array}{l}\text { Percent Voids Filled With } \\
\text { Asphalt (VFA) }\end{array}$ & & AASHTO PP-28 & \\
\hline
\end{tabular}

At the start of a construction project, constructors are required to verify that the mix produced at the plant faithfully replicates the volumetric parameters from the mix design. During verification, the constructor randomly collects a sample during each three hours of production, with no more than three samples per day. The volumetric and gradation parameters of the samples are evaluated and compared to the specification criteria for the mix design. If all the samples are within the requirements, the mix production is verified and the constructor proceeds with the construction. If the test parameters are outside of the specification limits, production adjustments are made and 
the constructor collects three additional samples. If the results from these samples are acceptable, production continues. Otherwise, the constructor must halt production until the plant or mix proportions are adjusted and verified.

Once a mix is verified, the normal QC/QA process is followed. The number of samples required is based on the following schedule:

Production time Sampling schedule

Less than six hours One sample

More than six hours but less One sample for each half of the production period than twelve hours

More than twelve hours $\quad$ One sample for first six hour period

One sample for the second six hour period

One sample for the remaining time

All samples are tested for the volumetric parameters, asphalt content and gradation. The results are evaluated for specification compliance based on a four-test moving average. Control charts are maintained and made available to the WVDOH for inspection. If the moving average of a test result, or three consecutive gradation results, falls outside of the specification limits, the production shall be halted until the constructor takes the necessary steps to bring the production under control. The quantity of material falling outside of the limits is computed and a price adjustment is applied.

\subsection{QUALITY ASSURANCE FOR SUPERPAVE}

While the constructor has responsibility for quality control, the WVDOH has the responsibility for verification of the quality control, or quality assurance. Three methods are allowed in the Division's MP 401.02.29 for quality verification:

1. By conducting independent sampling and testing

2. By witnessing or reviewing the constructor's sampling and testing or

3. By a combination of 1 and 2 .

When independent sampling and testing is conducted, the Division samples approximately $10 \%$ of the sampling rate specified in the constructor's quality control plan. Samples are tested in district offices by WVDOH technicians. The parameters 
evaluated for quality assurance are the same as the quality control parameters with the exception of the dust to binder ratio. This parameter is not evaluated during quality assurance. The procedures for evaluating the results of the QA tests are specified in WVDOH MP 700.00.54.

Samples are collected from the same location, stockpile, etc. as used for the QC samples. If the QA sample represents a material where more than five but less than 11 QC samples were taken, then the procedure is to compute the range and average of the QC samples then establish a comparison range for the QA results. If there are more than 10 QC samples, then only 10 samples, whose midpoint is nearest chronologically to the QA sample, are used for the analysis. The comparison range is computed as:

$L L=\bar{X}-c_{i} R, \quad U L=\bar{X}+c_{i} R$

Where:

$\mathrm{LL}=$ Lower limit

$\mathrm{UL}=$ Upper limit

$\bar{X}=$ Average of QC tests

$\mathrm{R}=$ Range

$c_{i}=$ coefficient based on the number of QC samples defined as:

\begin{tabular}{cc}
$\begin{array}{c}\text { Number of QC } \\
\text { Samples }\end{array}$ & $\begin{array}{c}\text { Coefficient, } \\
\mathrm{c}_{\mathrm{i}}\end{array}$ \\
\hline 5 & 1.61 \\
6 & 1.33 \\
7 & 1.17 \\
8 & 1.05 \\
9 & 0.97 \\
10 & 0.91 \\
\hline
\end{tabular}

If the QA does not fall within the range defined by UL and LL an investigation of the source of the discrepancy is performed. If there are fewer than $5 \mathrm{QC}$ samples, then the district materials engineer/supervisor has discretion in the evaluation of the test results. 


\subsection{STANDARD TEST METHODS FOR SUPERPAVE MIXES}

AASHTO and ASTM provide standard-testing procedures used in the evaluation of hot mix asphalt (HMA). Each organization publishes books stating a standard procedure by which tests should be carried out to obtain the least variable results. These tests may be identical in procedure and statistical variation of results, but are simply designated by a different test number. For example, the test for Sieve Analysis of Fine and Coarse Aggregates is designated as T 27-99 by AASHTO and C 136-96 by ASTM. Other tests have minor differences in the method or instrumentation used, which will vary the resulting precision and variability of the tests on the same material property test.

Table 2.3 provides a list of the volumetric quality control parameters, the equations used to calculate the parameters and the AASHTO and ASTM tests used to obtain the parameters. Table 2.4 provides a list of AASHTO and ASTM standard test methods that impact the quality control parameters of a HMA once the parameters are disaggregated to identify the individual tests and equations needed to determine the QC/QA parameters.

In calculating the $\mathrm{P}_{0.075}$ for $\mathrm{D} / \mathrm{B}$, two methods are available. The first method included the percent passing the $0.075 \mathrm{~mm}$ sieve of each stockpile being subject to a standard deviation from AASHTO T27. This method would then add the resulting percent passing the $0.075 \mathrm{~mm}$ sieve amounts and this value would be used in the D/B calculation. The second method involved adding the percent passing each stockpile together first. Then the standard deviation for a $500 \mathrm{~g}$ sample for passing the $0.075 \mathrm{~mm}$ sieve was used as the standard deviation. This standard deviation can also be found in AASHTO T27. 
Table 2.3: Volumetric Quality Control Parameters

\begin{tabular}{|c|c|c|}
\hline Volumetric Parameter & Equation & AASHTO \& ASTM Tests Required \\
\hline Air Voids (VTM) & $V T M=\left(1-\frac{G_{m b}}{G_{m m}}\right)$ & AASHTO T 166, T 209 \\
\hline $\begin{array}{l}\text { Voids in Mineral } \\
\text { Aggregate } \\
\text { (VMA) }\end{array}$ & $V M A=\left(1-\frac{G_{m b}\left(1-P_{b}\right)}{G_{s b}}\right)$ & $\begin{array}{c}\text { AASHTO T 27, T 84, T 85, T } 209 \\
\text { ASTM D } 70\end{array}$ \\
\hline $\begin{array}{l}\text { Voids Filled with } \\
\text { Asphalt } \\
\text { (VFA) }\end{array}$ & $V F A=\frac{V M A-V T M}{V M A}$ & $\begin{array}{c}\text { AASHTO T 27, T 84, T 85, T 166, T } 209 \\
\text { ASTM D } 70\end{array}$ \\
\hline Dust to Binder Ratio & $\begin{array}{l}G_{s e}=\frac{100-P_{b}}{\frac{100}{G_{m m}}-\frac{P_{b}}{G_{b}}} \quad P_{b a}=100\left(\frac{\left(G_{s e}-G_{s b}\right)}{\left(G_{s b} * G_{s e}\right)}\right) P_{b} \\
P_{b e}=P_{b}-\left(\frac{P_{b a}}{100}\right) P_{s} \quad D / B=\frac{\mathrm{P}_{0.075}}{P_{b e}}\end{array}$ & $\begin{array}{c}\text { AASHTO T } 11, \text { T } 27, \text { T 84, T 85, T } 209 \\
\text { ASTM D } 70\end{array}$ \\
\hline
\end{tabular}


Table 2.4: AASHTO and ASTM Test Methods Affecting Quality Control

\begin{tabular}{|c|c|}
\hline Test Number & Test Name \\
\hline AASHTO PP-28 & \\
\hline AASHTO TP 4 & \\
\hline AASHTO T 19/T 19M-00 & Bulk Density and Voids in Aggregate \\
\hline AASHTO T 27 & Sieve Analysis of Fine and Coarse Aggregates \\
\hline AASHTO T 84 & Specific Gravity and Absorption of Fine Aggregate \\
\hline AASHTO T 85 & Specific Gravity and Absorption of Coarse Aggregate \\
\hline AASHTO T 164 & Quantitative Extraction of Bituminous Paving Mixtures \\
\hline AASHTO T 166 & Bulk Specific Gravity of Compacted Asphalt Mixtures Using Saturated Surface-Dry Specimens \\
\hline AASHTO T 269 & Percent Air Voids in Compacted Dense and Open Bituminous Paving Mixtures \\
\hline AASHTO T304 & Uncompacted Void Content of Fine Aggregate \\
\hline AASHTO T308 (METHOD A) & Determining the Asphalt Binder Content of Hot-Mix Asphalt by Ignition Method \\
\hline ASTM D70-82 & Specific Gravity and Density of Semi-Solid Bituminous Materials \\
\hline ASTM D5821 & Determining the Percentage of Fractured Faces in Coarse Aggregate \\
\hline
\end{tabular}




\subsection{PRECISION STATEMENTS}

Precision statements are provided in the AASHTO and ASTM test methods used in evaluating asphalt mixture properties. These precision statements provide either the standard deviation or the coefficient of variation values for each test as well as an acceptable range between results. The coefficient of variation equals the standard deviation of a test method divided by the mean value of a set of tests, expressed in percent. The acceptable range for the difference between two tests equals the standard deviation or the percent coefficient of variation multiplied by $2.83(2 \sqrt{ } 2)$. This allowable range is termed the two-sigma limit, $\mathrm{d} 2 \mathrm{~s}$, when the standard deviation is provided or the $\mathrm{d} 2 \mathrm{~s}$ in percent when the coefficient of variation is given The two-sigma limit was selected to provide a $95 \%$ degree of confidence when making a comparative statement about the test results:

The d2s index is the difference between two individual test results that would be equaled or exceeded in the long run in only 1 case in 20 in the normal and correct operation of the method. (ASTM, 2000)

The precision statements include values for test results for within laboratory and between laboratory tests. The precision statement for the within laboratory is defined for a single technician testing samples using a single set of equipment in one laboratory. The between laboratory statement is for replicate samples tested in two different laboratories by different technicians, using similar equipment and conditions. Tables 2.5, 2.6, and 2.7 provide information from the precision statements for each test method used for quality control for both within and between laboratory results. Table 2.5 was compiled from the different test methods. Tables 2.6 and 2.7 were obtained from AASHTO test method $\mathrm{T}-27$. 
Table 2.5: Standard Deviations for Standard Test Methods

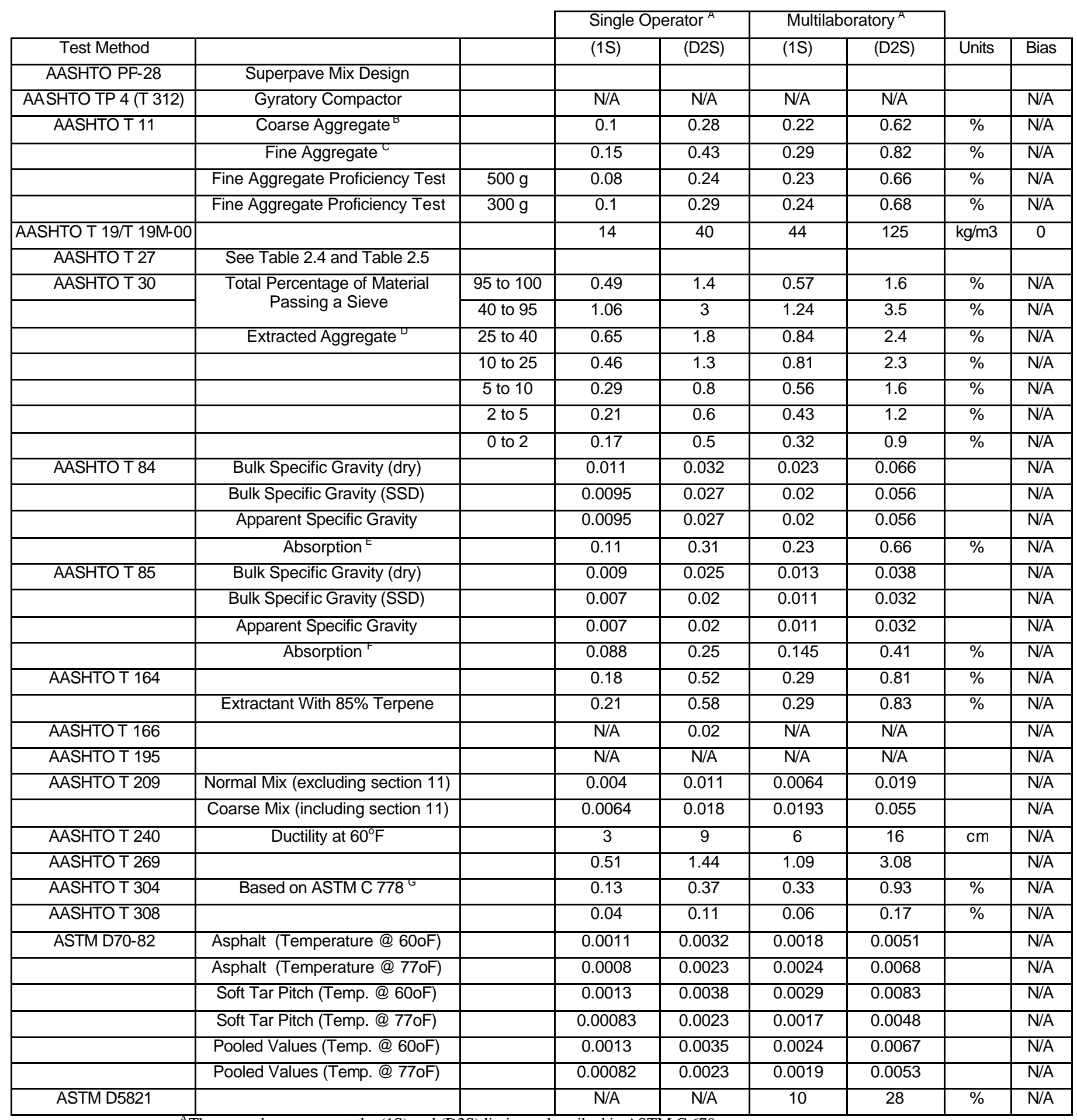

${ }^{\mathrm{A}}$ These numbers represent the (1S) and (D2S) limits as described in ASTM C 670

${ }^{\mathrm{B}}$ Precision estimates are based on aggregates having a nominal maximum size of $19.0 \mathrm{~mm}$ with less than 1.5 percent finer than the 75 um sieve.

${ }^{\mathrm{C}}$ Precision estimates are based on fine aggregates having 1.0 to 3.0 percent finer than the 75 um sieve.

${ }^{\mathrm{D}}$ The precision estimates are based on aggregates with nominal maximum sizes of $19.0 \mathrm{~mm}$ to $9.5 \mathrm{~mm}$.

${ }^{\mathrm{E}}$ Precision estimates are based on aggregates with absorptions of less than 1 percent and may differ for manufactured fine aggregates and fine aggregates having absorption values greater than 1 percent

${ }_{\mathrm{F}}^{\mathrm{F}}$ Precision estimates are based on aggregates with absorptions of less than 2 percent.

G Values obtained for standard deviations pertain to void contents determined on "graded standard sand" as described in

Specification C 778 . 
Table 2.6: Standard Deviations for AASHTO T-27

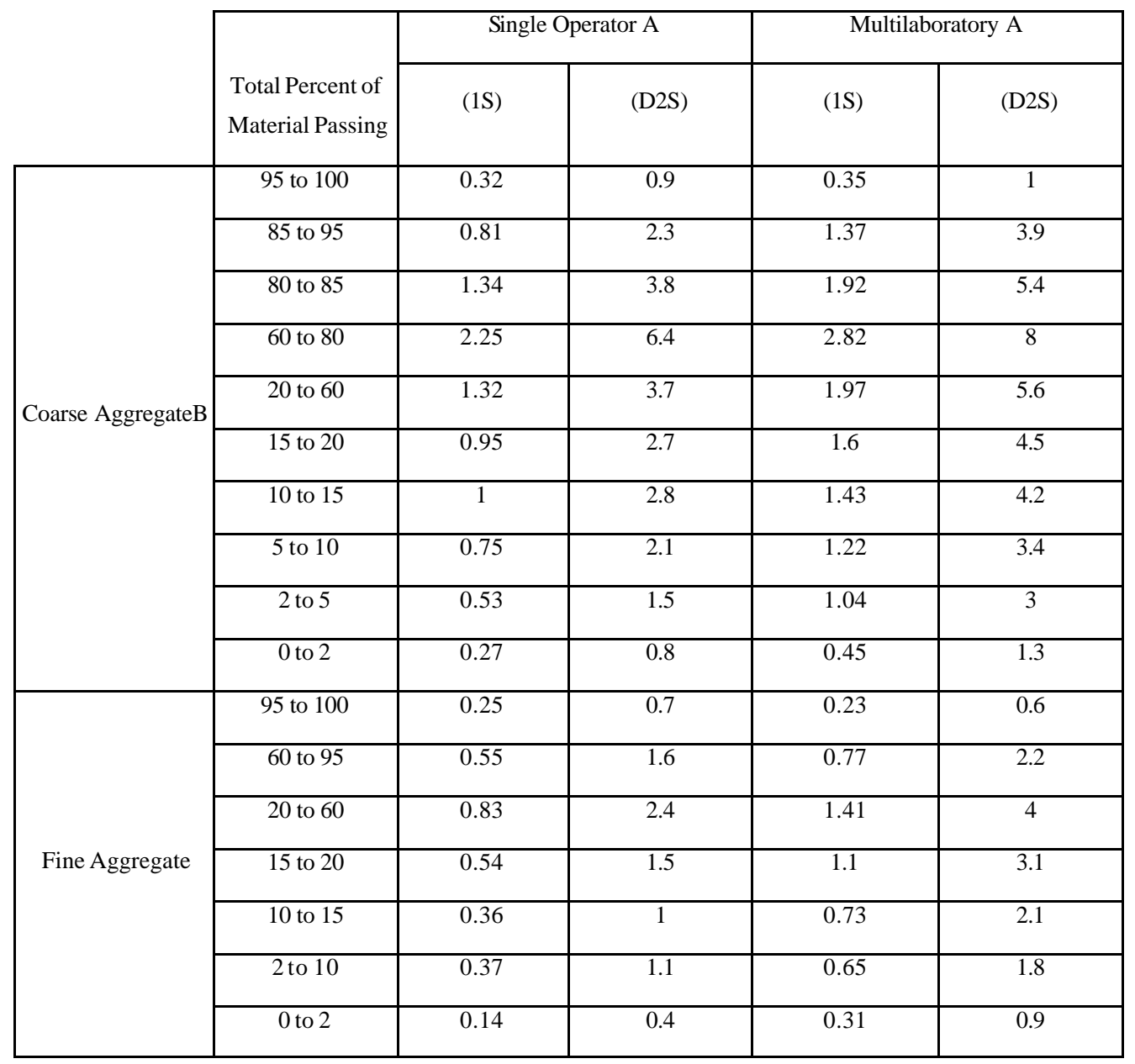

A These numbers represent, respectively, the (1sS) and (d2s) limits as described in ASTM C 670

B The precision estimates are based on aggregates with nominal maximum size of $19.0 \mathrm{~mm}$. 
Table 2.7: Standard Deviations for 300-g and 500-g Test Samples for AASHTO T-27

\begin{tabular}{|c|c|c|c|c|c|c|c|}
\hline \multirow{2}{*}{$\begin{array}{l}\text { Sample } \\
\text { Size (g) }\end{array}$} & \multirow{2}{*}{$\begin{array}{l}\text { Total Percent of } \\
\text { Material Passing }\end{array}$} & \multicolumn{2}{|c|}{ Single Operator } & \multicolumn{2}{|c|}{ Multilaboratory } & \multirow[b]{2}{*}{ Units } & \multirow[b]{2}{*}{ Bias } \\
\hline & & $(1 \mathrm{~S})$ & (D2S) & $(1 \mathrm{~S})$ & $(\mathrm{D} 2 \mathrm{~S})$ & & \\
\hline 500 & \multirow{2}{*}{ No. 4 Sieve } & 0.027 & 0.066 & 0.037 & 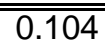 & $\%$ & $\bar{N} / \mathrm{A}$ \\
\hline 300 & & 0.021 & 0.06 & 0.042 & 0.117 & $\%$ & $\mathrm{~N} / \mathrm{A}$ \\
\hline 500 & \multirow{2}{*}{ No. 8 Sieve } & 0.43 & 1.21 & 0.63 & 1.76 & $\%$ & $\mathrm{~N} / \mathrm{A}$ \\
\hline 300 & & 0.39 & 1.29 & 0.69 & 1.92 & $\%$ & $\mathrm{~N} / \mathrm{A}$ \\
\hline 500 & \multirow{2}{*}{ No. 16 Sieve } & 0.53 & 1.49 & 0.75 & 2.1 & $\%$ & $\mathrm{~N} / \mathrm{A}$ \\
\hline 300 & & 0.52 & 1.74 & 0.76 & 2.12 & $\%$ & $\mathrm{~N} / \mathrm{A}$ \\
\hline 500 & \multirow{2}{*}{ No. 30 Sieve } & 0.75 & 2.1 & 1.33 & 3.73 & $\%$ & $\mathrm{~N} / \mathrm{A}$ \\
\hline 300 & & 0.87 & 2.44 & 1.36 & 3.79 & $\%$ & $\mathrm{~N} / \mathrm{A}$ \\
\hline 500 & \multirow{2}{*}{ No. 50 Sieve } & 0.42 & 1.17 & 0.98 & 2.73 & $\%$ & $\mathrm{~N} / \mathrm{A}$ \\
\hline 300 & & 0.45 & 1.25 & 0.99 & 2.75 & $\%$ & $\mathrm{~N} / \mathrm{A}$ \\
\hline 500 & \multirow{2}{*}{ No. 100 Sieve } & 0.15 & 0.42 & 0.37 & 1.03 & $\%$ & $\mathrm{~N} / \mathrm{A}$ \\
\hline 300 & & 0.18 & 0.52 & 0.32 & 0.89 & $\%$ & $\mathrm{~N} / \mathrm{A}$ \\
\hline 500 & \multirow{2}{*}{ No. 200 Sieve } & 0.11 & 0.32 & 0.31 & 0.85 & $\%$ & $\mathrm{~N} / \mathrm{A}$ \\
\hline 300 & & 0.14 & 0.39 & 0.31 & 0.85 & $\%$ & $\mathrm{~N} / \mathrm{A}$ \\
\hline
\end{tabular}

In addition to precision statements, bias statements are provided for the test methods. The bias in a test result is the difference between the true value of the property and the actual test result observed. The bias statements express whether any known difference between test results has been found. In many cases a bias cannot be determined for lack of a target value. None of the test methods used for QC/QA have a stated bias.

\subsection{MONTE CARLO SIMULATION}

The Monte Carlo simulation method was developed in 1949 by John von Neumann and Stanislav Ulam (Peterson, 1999) The Neumann and Ulam idea specifically designated the use of random sampling procedures for analyzing deterministic mathematical situations. The Monte Carlo method gained significance with the development of computers to automate the tedious calculations and repetitions (Peterson, 1999). Monte Carlo simulation is now used routinely in many diverse fields, from the 
simulation of complex physical phenomena such as radiation transport in the earth's atmosphere to the simulation of a Bingo game (USDOE, 2003). The simulation process allows the user to include the inherent uncertainty associated with each input parameter into the analysis. The output of a Monte Carlo simulation is a probability distribution describing the probability associated with each possible outcome.

The major components of a Monte Carlo simulation include the following:

- Probability distribution functions ( $p d f^{\prime} s$ ) - the physical (or mathematical) system must be described by a set of pdf's.

- Random number generator - a source of random numbers uniformly distributed on the unit interval must be available.

- Sampling rule - a prescription for sampling from the specified pdf's, assuming the availability of random numbers on the unit interval, must be given.

- Scoring (or tallying) - the outcomes must be accumulated into overall tallies or scores for the quantities of interest.

- Error estimation - an estimate of the statistical error (variance) as a function of the number of trials and other quantities must be determined.

- Variance reduction techniques - methods for reducing the variance in the estimated solution to reduce the computational time for Monte Carlo simulation

- Parallelization and vectorization - algorithms to allow Monte Carlo methods to be implemented efficiently on advanced computer architectures. (USDOE, 2003)

Figure 2.1 illustrates a general schematic for a Monte Carlo simulation (Hutchinson and Bandalos, 1997). The first step of a Monte Carlo simulation is to identify a deterministic model where multiple input variables are used to estimate a single value outcome. The next step requires that all variables or parameters be identified. Then, the type of probability distribution for each independent variable is established for the simulation model, (e.g. normal, beta, log normal, etc). Next, a random trial process is initiated to establish a probability distribution function for the deterministic situation being modeled. During each pass, a random value from the distribution function for each parameter is selected and used into the calculation. Multiple solutions are obtained by making a large number of passes through the program obtaining a solution for each pass. The appropriate number of passes for an analysis is a function of the number of input parameters, the complexity of the modeled situation, and the desired precision of the 
output. The final result of a Monte Carlo simulation is a probability distribution of the output parameter (Peterson, 1999).

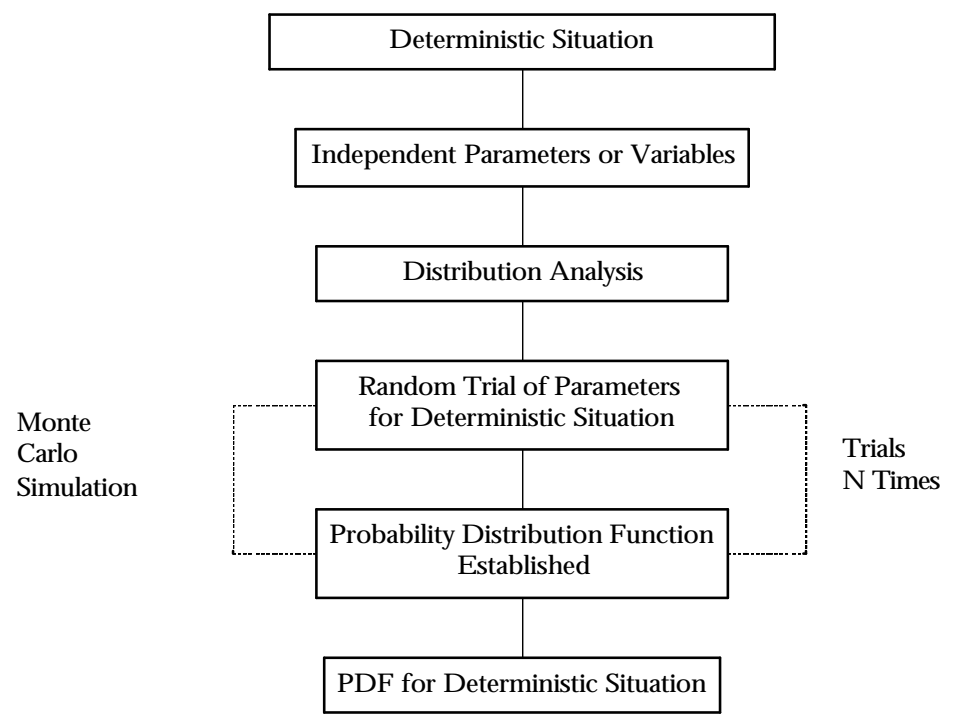

Figure 2.1: General Monte Carlo Simulation Approach

The Monte Carlo method requires numerous repetitive calculations and sampling of the distribution of the independent variables in the analysis. Even with modern computers, it is tedious to program a Monte Carlo simulation procedure. However, commercial tools are available to reduce the burden on the analysis for developing a Monte Carlo simulation. The @ Risk software is an add-in extension for Microsoft's Excel (Palisade Corporation, 1997). @Risk allows the user to select from a variety of distributions, perform the simulation, and then display the results of the simulation. @ Risk has been successfully used at WVU for the simulation of slope stability and evaluation of preventive maintenance strategies (Peterson, 1999 and Reigle, 2000)

One of the advantages of using the @ Risk software is the ability to readily define the type of distribution and sampling method used for the MCS. The Latin Hypercubic sampling procedure, available in @ Risk is designed to accurately recreate an input distribution through sampling in fewer iterations by stratification of the input probability distributions. Stratification divides a probability distribution cumulative curve into equal intervals on the cumulative probability scale ( 0 to 1.0$)$ from each interval or 
"stratification" of the input distribution (Palisade Corporation, 1997). The simulation begins with a randomly selected sample or value for each of the independent variables and the deterministic equations are exercised to compute independent variables in the analysis. A new set of values for the independent variables is established for the next step in the simulation. The simulation continues until the termination criteria are met. @ Risk allows termination of the simulation when either a fixed number of iterations are completed or when the mean and standard deviations changed by less than a userspecified amount. In the latter case, changes in the mean and standard deviations are tested after a user specified number of iterations.

Hand and Epps (2000) used Monte Carlo Simulation to assess the effects of variability in materials and mixture property measurements on volumetric properties and optimum asphalt content selection for the mix design of hot mix asphalt. Superpave and Marshall volumetric parameters were considered in this paper. The volumetric parameters of interest were VTM, VMA, VFA, percent compaction at initial $\left(\% \mathrm{G}_{\mathrm{mm} \text {,ini }}\right)$ and maximum $\left(\% \mathrm{G}_{\mathrm{mm} \text {,max }}\right)$ number of gyrations, and the dust to binder ratio. In order to calculate the volumetric parameters, the following properties were required:

- Asphalt content (AC)

- Combined aggregate bulk specific gravity $\left(\mathrm{G}_{\mathrm{sb}}\right)$

- Asphalt cement specific gravity $\left(\mathrm{G}_{\mathrm{b}}\right)$

- Bulk specific gravity of compacted specimens $\left(\mathrm{G}_{\mathrm{mb}}\right)$

- Theoretical maximum specific gravity of the mix $\left(\mathrm{G}_{\mathrm{mm}}\right)$

- The amount of material passing the $0.075 \mathrm{~mm}$ sieve $\left(\mathrm{P}_{0.075 \mathrm{~mm}}\right)$

The values of $\mathrm{AC}$ and $\mathrm{P}_{0.075 \mathrm{~mm}}$ are controlled in the laboratory for mix designs. The other properties are found experimentally. Therefore each property, $G_{b}, G_{s b}, G_{m b}$, and $\mathrm{G}_{\mathrm{mm}}$, have variability associated with its test method. Both AASHTO and ASTM test methods were researched to obtain precision statements. The $\mathrm{G}_{\mathrm{sb}}$, used in volumetric calculations, is the weighted average of the coarse and fine aggregate $\mathrm{G}_{\mathrm{sb}}$ values and thus has two individual standardized tests. The standard deviation for this property was also a 
weighted average of the standard deviations of the $\mathrm{G}_{\mathrm{sb}}$ test for coarse and fine aggregates. All other standard deviations are found from one test method.

The Monte Carlo Simulation was run using convergence of three parameters as the basis for the number of iterations performed. The standard deviation, mean, and percentiles ( 0 percent to 100 percent in 5 percent increments) for each output parameter were used as the convergence parameters. The convergence threshold of 0.75 percent was used for the termination point of the simulation. The simulation was evaluated every 100 iterations to check for the convergence threshold. The simulation was run using both within laboratory precision and between laboratory precisions. The results were then tabulated and discussed.

The results of the simulation presented the following distribution statistics for each volumetric property:

- Standard deviation

- Minimum observation

- Maximum observation

- Volumetric property values at plus and minus one standard deviation from the mean $(+1$ Std Dev and -1 Std Dev)

- Volumetric property values at plus and minus two standard deviation from the mean $(+2$ Std Dev and -2 Std Dev)

- $5^{\text {th }}, 10^{\text {th }}, 25^{\text {th }}, 50^{\text {th }}, 75^{\text {th }}, 90^{\text {th }}$, and $95^{\text {th }}$ percentiles.

Through the Monte Carlo simulation Hand and Epps (2000) demonstrated there was "tremendous" variability in the expected volumetric and mix design parameters as a result of the level of precision afforded by the testing methods. This research demonstrated that for a Superpave mix design where the optimum asphalt content for the "average" condition was 5.75 percent, the range in asphalt contents that is embraced within the 5 to 95 percentiles is 5.33 to more than 6.75 percent. This analysis was based on within lab variability. Larger ranges of results were obtained when the between lab precision statements were considered. Hand and Epps (2000) concluded: 
The effects of what is currently considered acceptable test variability on volumetrics and $\mathrm{AC}$ selection are unacceptable in light of the new types of specifications being implemented. These specifications place mix design responsibility on the contractor and mix design verification responsibility with the owner or agency. Verifying agencies are going to have to recognize the fact that variability exists and has a large potential impact to result in differences in mix design. This statement is also true for field management operations. This will ultimately drive the development of much needed mix design verification criteria and specifications.

\subsection{SUMMARY}

The specifications used by WVDOH represent the state-of-the-practice method for specifying and controlling the quality of HMA construction. While the design of the end product specification method is sound, the ability of these specifications is dependent on the precision of the test methods used to measure the control parameters. AASHTO and ASTM both include precision statements in all test methods used for HMA construction quality control and acceptance. Some of the parameters used for quality control and assurance are derived through a combination of test procedures making the determination of the variability of the parameter problematic. Monte Carlo simulation provides a technique for determining the overall variability of a process when that process is the result of several individual processes, each with its own variability. Hand and Epps (2000) performed a Monte Carlo simulation of the Marshall and Superpave mix design processes and concluded that the lack of precision in test methods and subsequently mix design parameters was unacceptable. They speculated that "field management", i.e. QC/QA, also suffers from a lack of precision in the testing method, but did not perform research to support this statement. 


\section{CHAPTER 3}

\section{RESEARCH METHODOLOGY}

\subsection{INTRODUCTION}

The literature review established the QC/QA method used by WVDOH, required test methods, and the fact that there are potential problems with the risks associated with the purchase decisions. The risk lies in accepting an unacceptable mix or accepting a substandard mix. Monte Carlo simulation was identified as a tool that could assist with determining the distribution of the QC/QA parameters as a function of the testing protocol with appropriate consideration of the variability of the test methods. The methodology was exercised for several mix designs that are typical of those constructed in West Virginia.

\subsection{RESEARCH APPROACH}

The evaluation of the QC/QA process involved several steps:

1. Review the WVDOH QC/QA methods

2. Identify QC/QA parameters

3. Identify tests required to quantify QC/QA parameters

4. Determine test method variability from the precision statement for each test method

5. Identify equations for computing QC/QA parameters from test results

6. Select method to quantify total variability in QC/QA parameter when multiple test methods are required.

7. Develop and verify models for quantifying parameter variability.

8. Exercise models for multiple mix types typically used by WVDOH.

9. Interpret results. 
The first four steps of this research approach were accomplished during the literature review as presented in Chapter 2. The equations needed for the analysis were also identified during the literature review. However, the structure for implementing these equations to determine the PDF for the QC/QA parameters is more explicitly set forth in the following.

Monte Carlo simulation was used for the sixth step in the procedure. Palisade's $@$ Risk add-in program for Excel was us ed for the quality control analysis. However, for the quality assurance analysis, additional parameter testing was required in a manner that is not convenient to capture in an @ Risk analysis. Therefore, a Visual Basic for Applications, VBA, program was developed to execute the quality assurance analysis. Exercising the models over simple data sets where the output could be predetermined validated both the @ Risk and VBA models.

Once the Monte Carlo models were developed and the associated variability of the test methods was identified, the models were exercised over a range of mix types used throughout the state. It was necessary to evaluate different mixes because:

1. The mean values of the mix design parameters change, establishing different acceptance ranges,

2. Some of the precision statements are expressed in percent coefficient of variation. In these cases, the variability of the test increases as the mean value for the test changes, and

3. The WVDOH quality control parameters are a function of the nominal maximum aggregate size for the mix.

The experiment was run using three mix designs of different classifications. The first mix design was a $37.5 \mathrm{~mm}$ Superpave mix followed by a $19 \mathrm{~mm} \operatorname{mix}$ and a $9.5 \mathrm{~mm}$ mix. The basic procedure used to test each mix type was similar; however, each mix type had different values for each property that had to be taken into consideration. To accommodate the changing variable values, a master file for using the @ Risk software and Excel was first created. The @ Risk software is the program that ran the Monte Carlo simulations for each of the test parameters that affects quality control. 


\subsection{QUALITY CONTROL MODEL}

Figure 3.1 shows how the Monte Carlo structure of Figure 2.1 was applied to this research. The MCS was applied to several mixes used in West Virginia, varying the nominal maximum aggregate size and the type of binder, as summarized in Table 3.1. First, the volumetric parameters evaluated during the analysis, and their associated equations are defined. These are represented as $\mathrm{y}_{\mathrm{k}}$ in Figure 3.1. The equations used in the MCS are presented in Table 2.3. This allows identification of the independent variables, represented as $\mathrm{x}_{\mathrm{j}}$ in Figure 3.1. For this analysis, four dependent variables used for quality control were evaluated, i.e. $x_{j}$ represents VTM, VMA, VFA, and D/B from Table 2.3. VMA and D/B are dependent on the bulk specific gravity of the aggregate, $\mathrm{G}_{\mathrm{sb}}$. The calculation of $\mathrm{G}_{\mathrm{sb}}$ is somewhat convoluted so the discussion of this parameter is deferred to a later section.

Table 3.1: Mix Design Types Evaluated with MCS

\begin{tabular}{|c|c|c|c|}
\multicolumn{1}{c|}{} & \multicolumn{3}{|c|}{ Binder Type } \\
\hline NMAS* & PG 64-22 & PG 70-22 & PG 76-22 \\
\hline \hline $9.5 \mathrm{~mm}$ & $\mathrm{X}$ & $\mathrm{X}$ & \\
\hline $12.5 \mathrm{~mm}$ & & & $\mathrm{X}$ \\
\hline $19 \mathrm{~mm}$ & $\mathrm{X}$ & $\mathrm{X}$ & \\
\hline $37.5 \mathrm{~mm}$ & $\mathrm{X}$ & & $\mathrm{X}$ \\
\hline
\end{tabular}

* Nominal Maximum Aggregate Size

In a deterministic analysis, a single value, typically the mean, is assigned to each independent variable. For this analysis, mean values from WVDOH T400 mix design sheets were used for each of the independent variables. Next, the parameter defining the distribution of each independent variable is determined. For this analysis, it was assumed by AASHTO and ASTM that all independent variables have a normal distribution, so their probability distribution function is completely defined by the mean and standard deviation. The standard deviation for each independent variable is defined as $\sigma_{j}$ on Figure 3.1 and is equal to the standard deviation determined from the precision statement for each test method. During the quality control process, constructor personnel perform all the testing in the constructor's laboratory. It was assumed that the precision statement 
for the within laboratory test condition applies to this situation. Note VFA is computed from VTM and VMA; this calculation was performed for each iteration during the simulation to determine the PDF for VFA. 


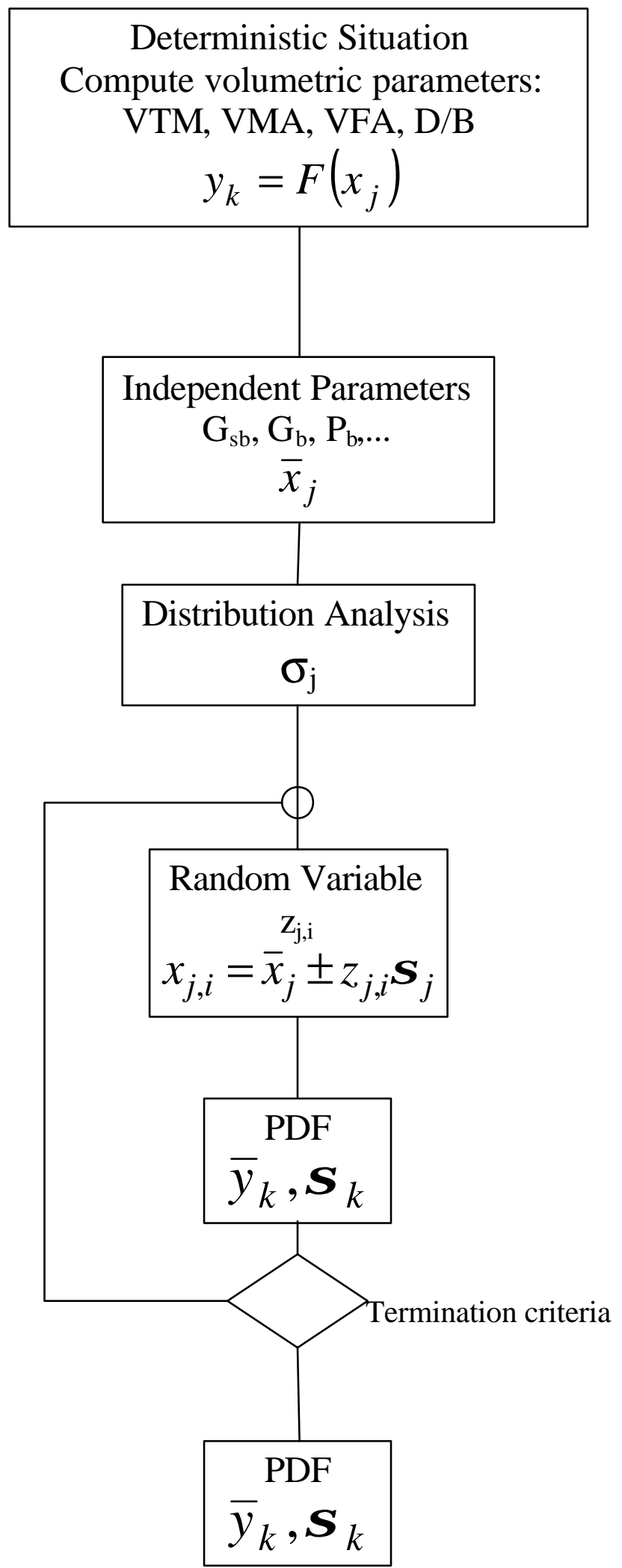

Figure 3.1: Flowchart of Quality Control Model 
With the equations and dependent variables defined, the Monte Carlo simulation was performed. Within @ Risk, a random variable was generated and used to "sample" the distribution for each of the independent variables and the deterministic equations are evaluated to determine a value for each dependent variable. For this analysis, a Latin Hypercubic sampling method was used. The statistics for the probability distribution function of the dependent variables are accumulated for each step in the simulation, followed by evaluation of the termination criteria. The simulation is terminated when the termination criteria are met. For this analysis, the simulation was terminated when there was less than a 0.75 percent difference between the means or standard deviations computed in increments of 100 simulation steps or when 10,000 simulation steps were completed.

The asphalt content of a mix, expressed as percent binder, $\mathrm{P}_{\mathbf{b}}$, is a quality control parameter. $\mathrm{P}_{\mathrm{b}}$ is measured directly using the ignition oven method, AASHTO T308. Since the expected value is known from the mix design and the standard deviation is known from the test method, it is not necessary or meaningful to determine the distribution of this parameter with MCS.

As shown on Figure 3.1, the output from the MCS is a probability distribution function for each of the dependent variables. Since the independent variables were normally distributed, all relationships in the simulation are linear functions, the resulting PDF is also normally distributed (Differences, 2005). Hence, the output probability distribution is completely defined by the mean and standard deviation.

\subsubsection{Standard Deviation of Sample of Means}

In performing the simulation, each iteration is a simulation of an individual test. The WVDOH QC/QA procedures are based on averaging four consecutive tests to determine the percent of the material that is within limits. In order to use the output from the MCS for evaluation of the WVDOH QC/QA specifications, it is necessary to adjust the standard deviation. The standard deviation of a sample of means is computed as (Cominsky, et al., 1998):

$$
\sigma_{\bar{x}}=\frac{\sigma}{\sqrt{n}}
$$


Where:

$\sigma_{\bar{x}}=$ standard deviation of sample means of sample size $\mathrm{n}$

$\sigma=$ standard deviation

$\mathrm{n}=$ number of samples averaged to obtain one result $(\mathrm{n}=4$; for WVDOH QC)

This equation resulted in all the standard deviations being divided by the square root of four, or simply dividing by two. The resulting value is termed the standard deviation of sample means.

\subsubsection{Percent Within Limits}

Once the PDF for each quality control parameter was determined from the MCS, the percent of test results either within or outside of the WVDOH control limits was calculated. The control limits are established using the parameters in Table 2.1. The Z value is a statistical value denoting the number of standard deviations that the upper or lower limits are from the mean value. The $\mathrm{Z}$ value was calculated as (Darlington and Carlson, 1975):

$Z=\frac{|C L \pm \bar{x}|}{\sigma_{\bar{x}}}$

Where:

$\mathrm{CL}=$ control limit, may be upper or lower control limit

$\bar{x}=$ mean

$\sigma_{\bar{x}}=$ standard deviation of sample means

This equation used the WVDOH upper and lower control limits for QC and the mean and standard deviation of means to establish two $\mathrm{Z}$ values. One value represents the upper limit and the other represents the lower limit. The Excel function NORMSDIST $(Z)$ was used to determine the percent outside the limit for a one -tailed test. The percent outside the limit is then subtracted from 100 to obtain the percent within either the upper or lower limits. 


\subsubsection{Aggregate Bulk Specific Gravity}

The aggregate bulk specific gravity, $\mathrm{G}_{\mathrm{sb}}$, is needed for the calculation of VMA and $\mathrm{D} / \mathrm{B}$. For HMA, $\mathrm{G}_{\mathrm{sb}}$ is a function of the blend percentages of the different stockpiles and the percent of material passing or retained on the $4.75 \mathrm{~mm}$ sieve. Within the scope of this research, these parameters are meaningful as there is a different level of precision when determining $\mathrm{G}_{\mathrm{sb}}$ for coarse versus fine aggregate. There is also a precision associated with the sieving of the aggregate to determine the amount of material in a stockpile that is retained on or passing the $4.75 \mathrm{~mm}$ sieve, i.e. coarse and fine aggregates, respectively.

The gradation results for each stockpile from the mix design report were used with the precision statement for gradation analysis to determine the percent of each stockpile material that was coarse or fine. The variability of the bulk specific gravity test was used with the mean specific gravity for a stockpile to simulate laboratory test results. The simulated results were used with the specific gravity blending equation to determine a combined bulk specific gravity for the coarse and fine aggregate in the mix. Then the blending equation was used to determine the bulk specific gravity for the blend of the aggregates. The aggregate blending equation is (Roberts, et al., 1996):

$$
G_{\text {sb blend }}=\frac{\sum P_{i}}{\sum\left(\frac{P_{i}}{G_{s b_{i}}}\right)}
$$

For example, a two stockpile blend with stockpile "A" being a fine material, $100 \%$ passing the $4.75 \mathrm{~mm}$ sieve, and stockpile "B" being an intermediate material with $29.7 \%$ passing the $4.75 \mathrm{~mm}$ sieve make up a mix. The percent of stockpiles in the blend was $40 \% \mathrm{~A}$ and $60 \% \mathrm{~B}$. The specific gravities of stockpile A and B are 2.654 and 2.678, respectively. The method used to combine these stockpiles to obtain one specific gravity and take into account the variation in testing is as follows:

Step 1: The standard deviations based on AASHTO T 27, Table 2.6, are used in accordance with the percent passing the $4.75 \mathrm{~mm}$ sieve.

$$
P_{4.75}^{\prime}=P_{4.75}+z \sigma=0.297+0.1 * .028=0.300
$$


At this point, the coarse and fine specific gravity values are subject to standard deviation based on AASHTO tests T85 and T84, respectively. These standard deviations are found in Table 2.5. A calculated specific gravity for both coarse and fine aggregate from each stockpile are found and used in the blend equation along with the calculated $\mathrm{P}_{4.75 \mathrm{~mm} \text { value. }}$

$$
\begin{gathered}
\frac{\text { Coarse }}{\left(\frac{60 * 0.7}{2.678}\right)}=2.678 \quad G_{\text {sbblend }}=\frac{60 * 0.3+40 * 1}{\left(\frac{60 * 0.3}{2.678}+\frac{40 * 1}{2.654}\right)}=2.661 \\
G_{\text {sbblend }}=\frac{60.7}{\left(\frac{6078}{2}\right)}
\end{gathered}
$$

Step 2: The blend equation is completed a second time to blend the coarse and fine aggregate specific gravity values. The example calculation is:

\section{$\underline{\text { Blend }}$}

$$
G_{\text {sbblend }}=\frac{42+58}{\left(\frac{42}{2.678}+\frac{58}{2.661}\right)}=2.668
$$

This blend specific gravity is the specific gravity used in the VMA equationand in calculating $\mathrm{D} / \mathrm{B}$. The value for the bulk specific gravity of the stone varies for each iteration of the simulation since it is based on standard deviations of the gradation and specific gravity tests.

The above procedure for considering the variation in gradation was also used to adjust the percent material passing the $0.075 \mathrm{~mm}$ sieve for the dust to binder ratio calculations. The adjusted bulk specific gravity is also used in determining the percent binder absorbed.

\subsubsection{Effects of Varying Asphalt Content}

The target asphalt content suggested by the results of the mix design is sometimes adjusted during plant production. The percent binder has an allowable range of plus or minus 0.4 percent from the accepted job mix formula, JMF. The addition or deduction of binder to a mix affects the volumetric parameters tested during quality control. By 
varying the percent binder in increments of tenths of a percent throughout the accepted range, simulations were performed to show the effect of the percent binder on volumetric parameters.

The "total percent within limits" for each volumetric property was computed and graphed verses the percent binder used in the simulation.

Varying the percent binder has a direct affect on VTM, $G_{m m}, G_{m b}, P_{b a}$, and $P_{b e}$. Therefore, to rerun the simulations using the different values for $P_{b}$, new values for $G_{m m}$, $\mathrm{G}_{\mathrm{mb}}$ and VTM were established for each $\mathrm{P}_{\mathrm{b}}$ simulated. The changes to $\mathrm{P}_{\mathrm{ba}}$ and $\mathrm{P}_{\mathrm{be}}$ were corrected by changing only the $\mathrm{P}_{\mathrm{b}}$ value. However, the value of $\mathrm{G}_{\mathrm{se}}$, which was calculated in simulating the target $P_{b}$, was used to calculate a new value for $G_{m m}$ using the equation:

$$
G_{m m}=\frac{100}{\frac{100-P_{b}}{G_{s e}}+\frac{P_{b}}{G_{b}}}
$$

The new value of VTM was found using the percent binder for each simulation and using the percent binder verses VTM graph from the mix design report. The new target VTM was read off the graph for the percent binder used in each simulation. The $\mathrm{G}_{\mathrm{mb}}$ was recalculated using:

$$
G_{m b}=\left(1-\frac{V T M}{100}\right) * G_{m m}
$$

Once these values were calculated for each $\mathrm{P}_{\mathrm{b}}$ per mix, the simulations were run using the same criteria as used in the target $\mathrm{P}_{\mathrm{b}}$ simulations. Each simulation was run using Latin Hypercubic Sampling, a $0.75 \%$ convergence and means and standard deviations were calculated for all volumetric parameters. It was assumed that the blend of aggregates in the mix remained constant.

\subsection{QUALITY ASSURANCE MODEL}

The structure of the quality assurance model used for the Monte Carlo simulation is shown in Figure 3.2. For this analysis, the probability distribution functions for each parameter were needed using both the within and between laboratory variances. These 
were obtained during the MCS used for the QC analysis. The PDF based on the within lab variance was used to model the constructor's test results. The PDF for the between lab results were used to model the QA results of the $\mathrm{WVDOH}$, due to the fact that the QA tests are performed by a different technician in a different lab.

The quality assurance procedure requires that the WVDOH collect and test independent samples to compare to the quality control results obtained by the constructor. Generally, the WVDOH tests one sample for each 10 samples tested by the constructor, but in some situations, a QA sample may be obtained for as few as 5 samples. Thus, the MCS was set up to simulate the effect of varying the number of constructor samples from 5 to 10 used in comparison to the QA sample. Following the requirements of Materials Procedure 700.00.54, the mean and range of QC test results were determined and the allowable range for the QA results was determined using the factors presented in Chapter 2. The results of the QA test were then simulated using the PDF for between laboratories. The simulated QA result was compared to the allowable range. If the QA result was outside the allowable range, a counter was incremented. This process was repeated for 1000 iterations and the percent of times the QA results was outside the allowable range was determined for each QC parameter. The simulation was repeated for each mix type evaluated during the QC analysis.

Due to the nature of the QA analysis, it was more convenient to write a simple Visual Basic for Applications program to perform this simulation rather than using @ Risk. The code for this program is presented in Appendix 2. 
Figure 3.2: Flowchart of Quality Assurance Model

Constructor QC tests

DOH QA tests

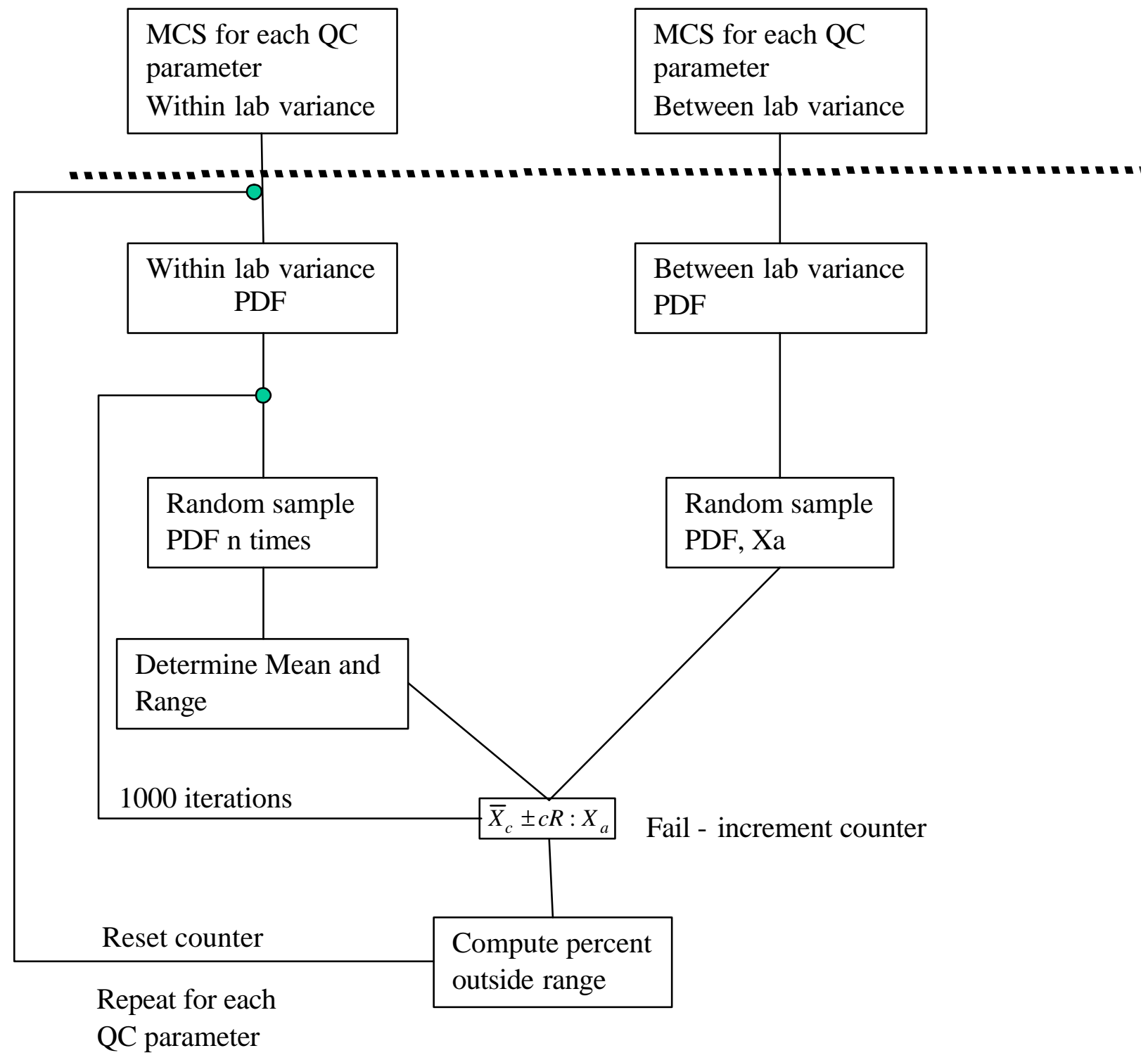




\section{CHAPTER 4}

\section{METHODOLOGY APPLICATION AND RESULTS}

\subsection{INTRODUCTION}

The methodology presented in Chapter 3 was completed using 7 mix designs for both within laboratory and between laboratory situations. The mix designs were composed of different gradations and different asphalt binder grades. The various gradations were $9.5 \mathrm{~mm}, 12.5 \mathrm{~mm}, 19 \mathrm{~mm}$, and $37.5 \mathrm{~mm}$. The various asphalt binders consisted of PG 64-22, PG 70-22, and PG 76-22. The seven mix designs that were simulated can be found in Table 3.1. The probability distribution function of each volumetric quality control parameter was evaluated and compared based on the current WVDOH quality control specifications.

\subsection{DESIGN INPUT AND OUTPUT VALUES}

To simulate each mix design, a number of input values must be entered in the spreadsheet for calculations. These inputs, which are discussed in Chapter 3, vary from one mix design to another. A summary of the required inputs and the values used for the input variables in each mix design can be found in Table 4.1. The input variables are used in the simulation to calculate the output variables specified by the user.

The outputs of interest for volumetric specifications are percent binder, VTM, VMA, VFA, and Dust to Binder Ratio (D/B). The needed statistical outputs for each volumetric parameter included the mean and the standard deviation calculated during the simulation. The mean and standard deviation values obtained for each output variable for each mix design can be found in Table 4.2 and Table 4.3 for the within and between laboratory variations, respectively. The within variations were used for the evaluation of the Quality Control parameters and the between variations were used to simulate the Quality Assurance analysis. 
Table 4.1: Input Variables for Monte Carlo Simulation

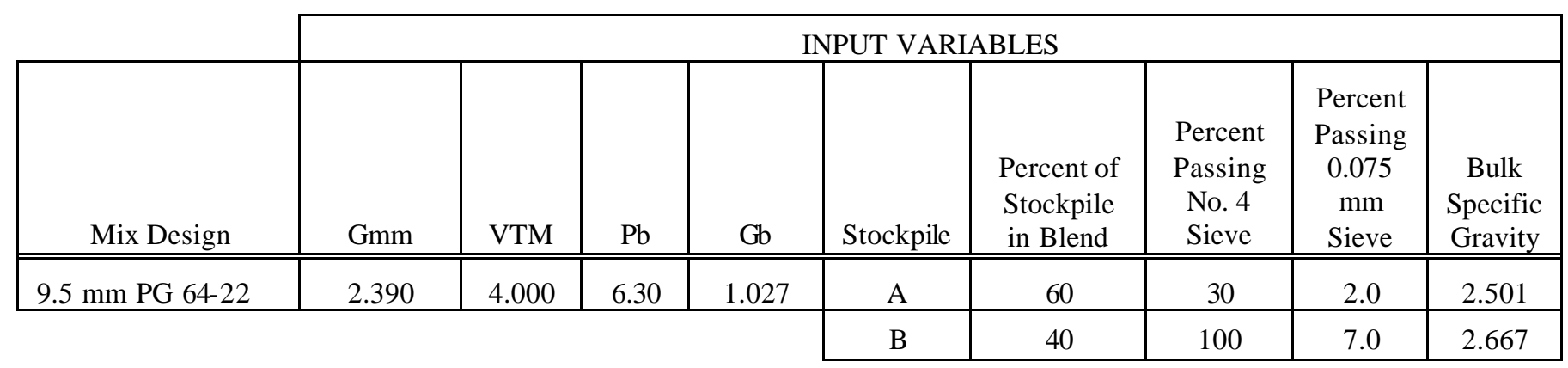

\begin{tabular}{|l|l|l|l|l|l|l|l|l|l|}
\hline $9.5 \mathrm{~mm}$ PG 70-22 & 2.491 & 4.000 & 5.70 & 1.042 & $\mathrm{~A}$ & 35 & 0 & 1.1 & 2.693 \\
\hline
\end{tabular}

\begin{tabular}{|l|l|l|l|l|l|l|l|l|l|}
\hline $12.5 \mathrm{~mm}$ PG 76-22 & 2.514 & 4.000 & 5.10 & 1.030 & $\mathrm{~A}$ & 35 & 0 & 2.1 & 2.621 \\
\hline
\end{tabular}

\begin{tabular}{|l|l|l|l|l|l|l|l|l|l|}
\hline $19 \mathrm{~mm}$ PG 64-22 & 2.469 & 4.000 & 4.94 & 1.028 & A & 41 & 0 & 3.2 & 2.633 \\
\hline
\end{tabular}

\begin{tabular}{|l|l|l|l|l|l|l|l|l|l|}
\hline $19 \mathrm{~mm}$ PG 70-22 & 2.514 & 4.000 & 4.80 & 1.032 & $\mathrm{~A}$ & 15 & 0 & 0.4 & 2.707 \\
\hline
\end{tabular}

\begin{tabular}{|c|c|c|c|c|c|c|c|c|c|}
\hline $37.5 \mathrm{~mm}$ PG $64-22$ & 2.556 & 4.000 & 3.60 & 1.041 & $\mathrm{~A}$ & 45 & 0 & 0.3 & 2.696 \\
\hline & & & & & $\mathrm{B}$ & 32 & 37 & 6.3 & 2.662 \\
\hline & & & & & $\mathrm{C}$ & 10 & 22 & 1.3 & 2.705 \\
\hline & & & & & $\mathrm{D}$ & 13 & 100 & 1.0 & 2.644 \\
\hline
\end{tabular}

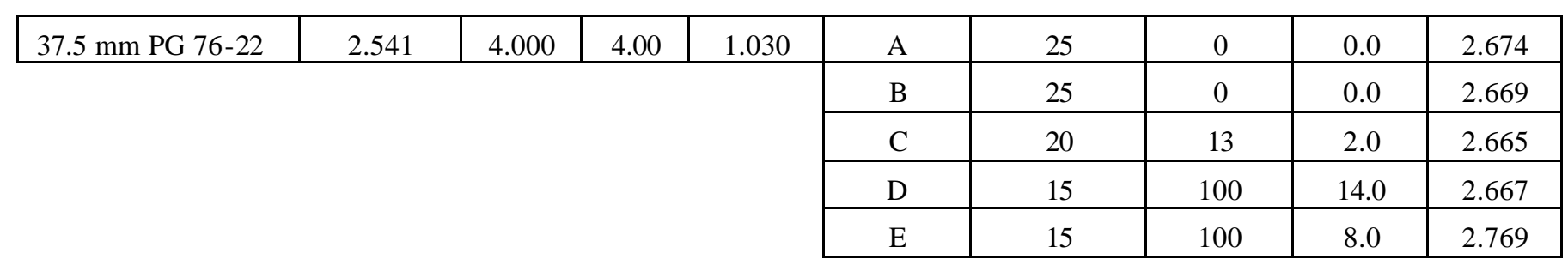


Table 4.2: Results of Within Laboratory Data

\begin{tabular}{|c|c|c|c|c|c|c|c|c|c|}
\hline Mix Type & $\begin{array}{l}\text { Binder } \\
\text { Type }\end{array}$ & $\begin{array}{l}\text { Number } \\
\text { of } \\
\text { Iterations }\end{array}$ & Statistic & $\begin{array}{l}\text { Percent } \\
\text { Binder } \\
(\mathrm{Pb})\end{array}$ & $\begin{array}{l}\text { Voids in } \\
\text { Total } \\
\text { Mix } \\
\text { (VTM) }\end{array}$ & $\begin{array}{l}\text { Voids in } \\
\text { Mineral } \\
\text { Aggregate } \\
\text { (VMA) }\end{array}$ & $\begin{array}{l}\text { Voids } \\
\text { Filled with } \\
\text { Asphalt } \\
\text { (VFA) }\end{array}$ & $\begin{array}{l}\text { Dust to } \\
\text { Binder } \\
\text { Ratio } \\
\text { (D/B) }\end{array}$ & $\begin{array}{c}\text { Dust to Binder } \\
\text { Ratio (D/B) } \\
\text { (500 g samples) }\end{array}$ \\
\hline \multirow[b]{2}{*}{$9.5 \mathrm{~mm}$} & \multirow[b]{2}{*}{ PG 64-22 } & \multirow{2}{*}{1900} & Mean & 6.3 & 4.0 & 16.20 & 75.30 & 0.80 & 0.80 \\
\hline & & & Std. Dev. ${ }^{*}$ & 0.021 & 0.259 & 0.250 & 1.631 & 0.004 & 0.010 \\
\hline \multirow[b]{2}{*}{$9.5 \mathrm{~mm}$} & \multirow[b]{2}{*}{ PG 70-22 } & \multirow{2}{*}{2000} & Mean & 5.7 & 4.0 & 15.20 & 73.50 & 0.90 & 0.90 \\
\hline & & & Std. Dev.* & 0.020 & 0.256 & 0.240 & 1.742 & 0.005 & 0.011 \\
\hline \multirow[b]{2}{*}{$12.5 \mathrm{~mm}$} & \multirow[b]{2}{*}{ PG 76-22 } & \multirow{2}{*}{1900} & Mean & 5.1 & 4.0 & 14.10 & 71.80 & 0.80 & 0.80 \\
\hline & & & Std. Dev.* & 0.020 & 0.252 & 0.231 & 1.844 & 0.005 & 0.012 \\
\hline \multirow[b]{2}{*}{$19 \mathrm{~mm}$} & \multirow[b]{2}{*}{ PG 64-22 } & \multirow{2}{*}{1800} & Mean & 4.9 & 4.0 & 13.50 & 70.20 & 1.10 & 1.10 \\
\hline & & & Std. Dev.* & 0.020 & 0.257 & 0.248 & 1.996 & 0.005 & 0.013 \\
\hline \multirow[b]{2}{*}{$19 \mathrm{~mm}$} & \multirow[b]{2}{*}{ PG 70-22 } & \multirow{2}{*}{2000} & Mean & 4.8 & 4.0 & 13.90 & 71.30 & 0.80 & 0.80 \\
\hline & & & Std. Dev.* & 0.020 & 0.263 & 0.242 & 1.973 & 0.004 & 0.013 \\
\hline \multirow[b]{2}{*}{$37.5 \mathrm{~mm}$} & \multirow[b]{2}{*}{ PG 64-22 } & \multirow{2}{*}{6800} & Mean & 3.6 & 4.0 & 11.70 & 65.80 & 0.70 & 0.70 \\
\hline & & & Std. Dev.* & 0.023 & 0.254 & 0.239 & 2.292 & 0.005 & 0.016 \\
\hline \multirow[b]{2}{*}{$37.5 \mathrm{~mm}$} & \multirow[b]{2}{*}{ PG 76-22 } & \multirow{2}{*}{1900} & Mean & 4.0 & 4.0 & 12.70 & 68.60 & 1.00 & 1.00 \\
\hline & & & Std. Dev.* & 0.021 & 0.250 & 0.235 & 2.072 & 0.005 & 0.015 \\
\hline
\end{tabular}

* Standard Deviation of Means 
Table 4.3: Results of Between Laboratory Data

\begin{tabular}{|c|c|c|c|c|c|c|c|c|c|}
\hline Mix Type & $\begin{array}{l}\text { Binder } \\
\text { Type }\end{array}$ & $\begin{array}{l}\text { Number } \\
\text { of } \\
\text { Iterations }\end{array}$ & Statistic & $\begin{array}{c}\text { Percent } \\
\text { Binder } \\
(\mathrm{Pb})\end{array}$ & $\begin{array}{l}\text { Voids in } \\
\text { Total } \\
\text { Mix } \\
\text { (VTM) }\end{array}$ & $\begin{array}{l}\text { Voids in } \\
\text { Mineral } \\
\text { Aggregate } \\
\text { (VMA) }\end{array}$ & $\begin{array}{l}\text { Voids } \\
\text { Filled with } \\
\text { Asphalt } \\
\text { (VFA) }\end{array}$ & $\begin{array}{l}\text { Dust to } \\
\text { Binder } \\
\text { Ratio } \\
\text { (D/B) }\end{array}$ & $\begin{array}{c}\text { Dust to } \\
\text { Binder Ratio } \\
\text { (D/B) } \\
(500 \mathrm{~g} \\
\text { samples }) \\
\end{array}$ \\
\hline \multirow[b]{2}{*}{$9.5 \mathrm{~mm}$} & \multirow[b]{2}{*}{ PG 64-22 } & \multirow{2}{*}{1900} & Mean & 6.3 & 4.0 & 16.20 & 75.00 & 0.80 & 0.80 \\
\hline & & & Std. Dev. & 0.062 & 1.094 & 1.047 & 6.957 & 0.010 & 0.051 \\
\hline \multirow[b]{2}{*}{$9.5 \mathrm{~mm}$} & \multirow[b]{2}{*}{ PG 70-22 } & \multirow{2}{*}{2000} & Mean & 5.7 & 4.0 & 15.20 & 73.50 & 0.90 & 0.90 \\
\hline & & & Std. Dev. & 0.060 & 1.116 & 1.008 & 7.689 & 0.012 & 0.056 \\
\hline \multirow[b]{2}{*}{$12.5 \mathrm{~mm}$} & \multirow[b]{2}{*}{ PG 76-22 } & \multirow{2}{*}{1900} & Mean & 5.1 & 4.0 & 14.20 & 71.60 & 0.80 & 0.80 \\
\hline & & & Std. Dev. & 0.059 & 1.090 & 0.958 & 8.004 & 0.012 & 0.061 \\
\hline \multirow[b]{2}{*}{$19 \mathrm{~mm}$} & \multirow[b]{2}{*}{ PG 64-22 } & \multirow{2}{*}{1800} & Mean & 4.9 & 4.0 & 13.40 & 69.90 & 1.10 & 1.10 \\
\hline & & & Std. Dev. & 0.060 & 1.073 & 1.051 & 8.408 & 0.014 & 0.064 \\
\hline \multirow[b]{2}{*}{$19 \mathrm{~mm}$} & \multirow[b]{2}{*}{ PG 70-22 } & \multirow{2}{*}{2000} & Mean & 4.8 & 4.0 & 13.90 & 71.30 & 0.80 & 0.80 \\
\hline & & & Std. Dev. & 0.062 & 1.091 & 1.047 & 8.206 & 0.012 & 0.064 \\
\hline \multirow[b]{2}{*}{$37.5 \mathrm{~mm}$} & \multirow[b]{2}{*}{ PG 64-22 } & \multirow{2}{*}{6800} & Mean & 3.6 & 4.0 & 11.70 & 65.60 & 0.70 & 0.70 \\
\hline & & & Std. Dev. & 0.067 & 1.093 & 0.999 & 9.882 & 0.013 & 0.087 \\
\hline \multirow[b]{2}{*}{$37.5 \mathrm{~mm}$} & \multirow[b]{2}{*}{ PG 76-22 } & \multirow{2}{*}{1900} & Mean & 4.0 & 4.0 & 12.70 & 68.80 & 1.00 & 1.00 \\
\hline & & & Std. Dev. & 0.059 & 1.086 & 0.965 & 8.868 & 0.016 & 0.079 \\
\hline
\end{tabular}




\subsection{PROBABILITY DISTRIBUTIONS OF OUTPUT VARIABLES}

The mean and standard deviations found during the Monte Carlo Simulation relate to a probability distribution for each output. The simulation creates the probability distribution through statistically associating the results of multiple iterations. The means and standard deviations are the only parameters needed to define the probability distribution functions since all distributions evaluated during this research were normally distributed.

\subsubsection{Quality Control Analysis}

The mean and standard deviation of each output variable were compared to the WVDOH specifications for probability of passing each quality control parameter for within laboratory variation. The method used to evaluate these parameters is shown using the $9.5 \mathrm{~mm}$ mix with PG 64-22 binder as an example.

The results from the $9.5 \mathrm{~mm}$ mix with PG 64-22 binder was compared to the WVDOH specifications for probability of passing each quality control parameter. The basic statistical method used was the percent within limits. The area under the curve is the percent chance that the output variable will meet the WVDOH specifications. Table 4.4 shows the $\mathrm{Z}$ values and percent within limits obtained for each output parameter for the $9.5 \mathrm{~mm}$ mix with PG 64-22 binder.

The table shows, for example, that VTM will be within the WVDOH specification limits 98.98 percent of the time. This value was obtained from the upper and lower control limits being 5.2 and 2.8, respectively. These values represent the tolerance of plus or minus $1.2 \%$ of the mean or $4 \%$ air voids. The standard deviation of means was 0.259. Using the Equation 3.2, $\mathrm{Z}$ is found to be 2.32 for both the upper and lower limits. This value when found in a statistical Z-value table will represent 1.02 percent outside the limit for a one tailed test. The percent within limit would be 100 minus this percent. The result of 99.06 percent represents half the curve. Since both $\mathrm{Z}$ values are equivalent in this instance, the other half of the curve has 98.98 percent within limits also. The total percent within limits is 97.96 percent.

A summary of the percent within limits of each output parameter for each mix design is presented in Table 4.5, and the details presented in Appendix 1. The results in 
Table 4.5 show that percent binder, voids in the total mix, voids in the mineral aggregate, and dust to binder ratio are not likely to fall outside the acceptable range set by the WVDOH due to variations associated with the test method. Both $\mathrm{P}_{\mathrm{b}}, \mathrm{VMA}$, and D/B have a very high percent falling within the limits. The only exception is for the dust to binder criteria for the $12.5 \mathrm{~mm}$ mix. The results show that the property only passes 50 percent of the time. This is due to the mix design showing the limits as 0.8 to 1.6, and the mean being at 0.78 . There is potentially a mistake in the mix design documents. In some cases, the $\mathrm{D} / \mathrm{B}$ criteria have a range of 0.6 to 1.2 . If this is the case, the percent within limits is $100 \%$.

The questionable criteria limits occur for voids filled with asphalt. The range of acceptable limits is 65 to 92 for VFA. These percent within limits are quite variable and indicate that, in some cases, the variability due to the testing methods would cause rejection of an acceptable material. These results support the decision by the WVDOH to remove VFA from the quality control requirements (Epperly, 2003) 
Table 4.4: $9.5 \mathrm{~mm}$ mix with PG 64-22 Statistics

\begin{tabular}{|c|c|c|c|c|c|c|c|c|c|c|c|c|c|}
\hline \multicolumn{5}{|l|}{$9.5 \mathrm{~mm}$ mix with PG 64-22 } & \multicolumn{2}{|c|}{ Control Limits } & \multicolumn{2}{|c|}{$\mathrm{Z}$ value } & \multicolumn{2}{|c|}{$\begin{array}{c}\text { Percent Outside } \\
\text { Limit* }\end{array}$} & \multicolumn{2}{|c|}{ Percent Within Limit* } & \\
\hline Volumetric Parameter & JMF & Mean & Std. Dev. & $\begin{array}{l}\text { Std. Dev. } \\
\text { for Means }\end{array}$ & Lower & Upper & Lower & Upper & Lower & Upper & Lower & Upper & $\begin{array}{l}\text { Total Percent } \\
\text { Within Limit }\end{array}$ \\
\hline Percent Binder & 6.3 & 6.3 & 0.041 & 0.021 & $\overline{5.9}$ & 6.7 & 9.76 & 9.76 & $\overline{0}$ & 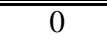 & 100 & 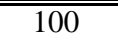 & 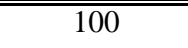 \\
\hline Voids in Total Mix & 4.0 & 4.0 & 0.518 & 0.259 & 2.8 & 5.2 & 2.32 & 2.32 & 1.02 & 1.02 & 98.98 & 98.98 & 97.96 \\
\hline Voids in Mineral Aggregate & 16.0 & 16.2 & 0.499 & 0.250 & 15.0 & 17.0 & 2.4 & 1.6 & 0.82 & 5.48 & 99.18 & 94.52 & 93.7 \\
\hline Voids Filled with Asphalt & 75.0 & 75.3 & 3.261 & 1.631 & 63.0 & 77.0 & 3.77 & 0.52 & 0.01 & 30.15 & 99.99 & 69.85 & 69.84 \\
\hline Dust to Binder Ratio & 0.7 & 0.8 & 0.008 & 0.004 & 0.6 & 1.2 & 25 & 50 & 0 & 0 & 100 & 100 & 100 \\
\hline Dust to Binder Ratio (500 g sample) & & 0.8 & 0.019 & 0.010 & 0.6 & 1.2 & 10.53 & 21.05 & 0 & 0 & 100 & 100 & 100 \\
\hline
\end{tabular}


Table 4.5: Within Laboratory PWL Results

\begin{tabular}{|l|c|c|c|c|c|c|c|}
\cline { 2 - 8 } \multicolumn{1}{c|}{} & \multicolumn{6}{c|}{ Total Percent Within Limits } \\
\hline \multicolumn{1}{c|}{ Volumetric Parameter } & $\begin{array}{c}9.5 \mathrm{~mm} \\
\text { PG 64-22 }\end{array}$ & $\begin{array}{c}9.5 \mathrm{~mm} \\
\text { PG 70-22 }\end{array}$ & $\begin{array}{c}12.5 \mathrm{~mm} \\
\text { PG 76-22 }\end{array}$ & $\begin{array}{c}19 \mathrm{~mm} \text { PG } \\
64-22\end{array}$ & $\begin{array}{c}19 \mathrm{~mm} \text { PG } \\
70-22\end{array}$ & $\begin{array}{c}37.5 \mathrm{~mm} \\
\text { PG 64-22 }\end{array}$ & $\begin{array}{c}37.5 \mathrm{~mm} \\
\text { PG 76-22 }\end{array}$ \\
\hline \hline Percent Binder & 100 & 100 & 100 & 100 & 100 & 100 & 100 \\
\hline Voids in Total Mix & 97.96 & 98.08 & 98.26 & 98.08 & 97.74 & 98.18 & 98.36 \\
\hline Voids in Mineral Aggregate & 93.7 & 92.45 & 90.2 & 93.96 & 95.73 & 96.42 & 92.91 \\
\hline Voids Filled with Asphalt & 69.84 & 84 & 91.23 & 91.95 & 90.72 & 64.44 & 84.53 \\
\hline Dust to Binder Ratio & 100 & 100 & 50 & 100 & 100 & 100 & 100 \\
\hline $\begin{array}{l}\text { Dust to Binder Ratio (500 g } \\
\text { sample) }\end{array}$ & 100 & 100 & 50 & 100 & 100 & 99.94 & 100
\end{tabular}




\subsubsection{Effect of Varying Asphalt Content}

The results of the simulations for varying the percent binder in a mix are presented in Figure 4.1. In general, VMA is not affected enough by changes in $\mathrm{P}_{\mathrm{b}}$ to cause any chance of rejection based on the variation in the test methods alone. The D/B is not dramatically affected in 5 of the 7 mix designs when the $\mathrm{P}_{\mathrm{b}}$ is varied within tolerance limits. However, it is clear that percent binder has a large impact on the VFA results. VTM is also affected, but not as significantly as the VFA parameter.

The D/B results for the $37.5 \mathrm{~mm}$ with PG 64-22 binder in Figure 4.1(f) shows that after an increase in $\mathrm{P}_{\mathrm{b}}$ of more than one-tenth percent, there is not enough dust in the mix to keep the dust to binder ratio above the lower limit. The other D/B exception is the 12.5-mm mix with PG 76-22 binder, Figure 4.1(c). As discussed above, the reason for this high percent outside of the limits is likely due to an error in the mix design report. The changing $\mathrm{P}_{\mathrm{b}}$ does not show a change in acceptance of the $\mathrm{D} / \mathrm{B}$ criteria, but instead the results were only within limits fifty percent of the time.

The VFA showed the most variability in being accepted or rejected based on the change in $\mathrm{P}_{\mathrm{b}}$. In most of the mixes, the VFA results would be likely to be rejected, as the percent binder was varied from the accepted target value from the JMF. The figures also show that the percent VFA within limits is sometimes higher for asphalt contents other than the approved JMF value. In some cases, increasing or decreasing the percent binder by one-tenth percent will increase the probability that tests will indicate the mix is within the VFA specification limits. It appears that the percent within limits decreases as the asphalt content is increased above the JMF value for the $9.5 \mathrm{~mm}$ mixes. The percent within limits for VFA decreases with either an increase or decrease in asphalt content for the $19 \mathrm{~mm}$ mixes. For the $37.5 \mathrm{~mm}$ mixes, the percent VFA within limits decreases for asphalt contents less than the JMF target.

The results for VTM verses percent binder show somewhat of an umbrella-shape effect. The acceptance of VTM remains high for the mixes as long as the $\mathrm{P}_{\mathrm{b}}$ stays within about two-tenths of the target $\mathrm{P}_{\mathrm{b}}$. However, if the change $\mathrm{P}_{\mathrm{b}}$ exceeds two-tenths, then the percent within limits of the VTM results decreases rapidly. 
Figure 4.1: Percent Within Limits with Varying Percent Binder
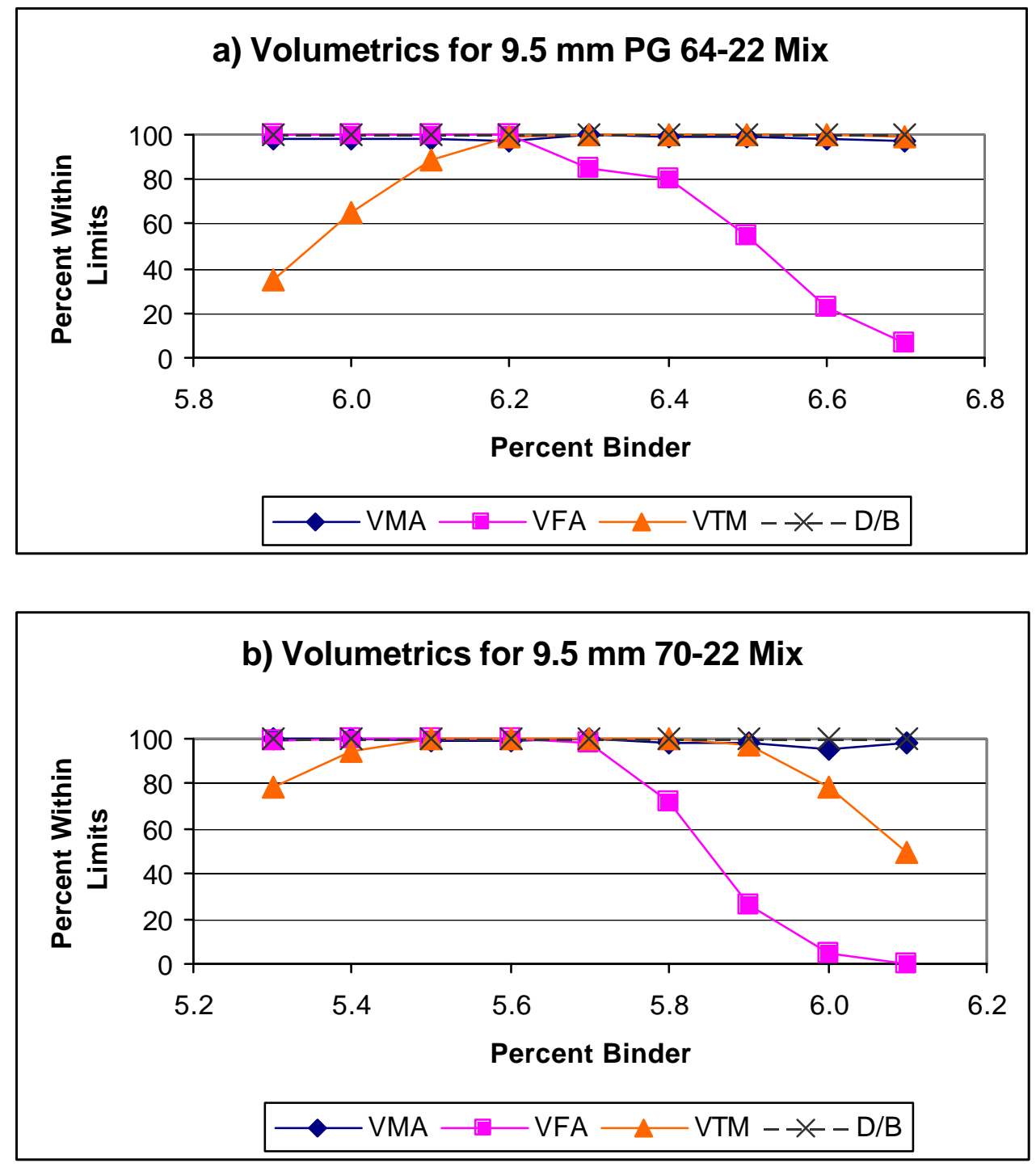


\section{c) Volumetrics for $12.5 \mathrm{~mm}$ 76-22 Mix}

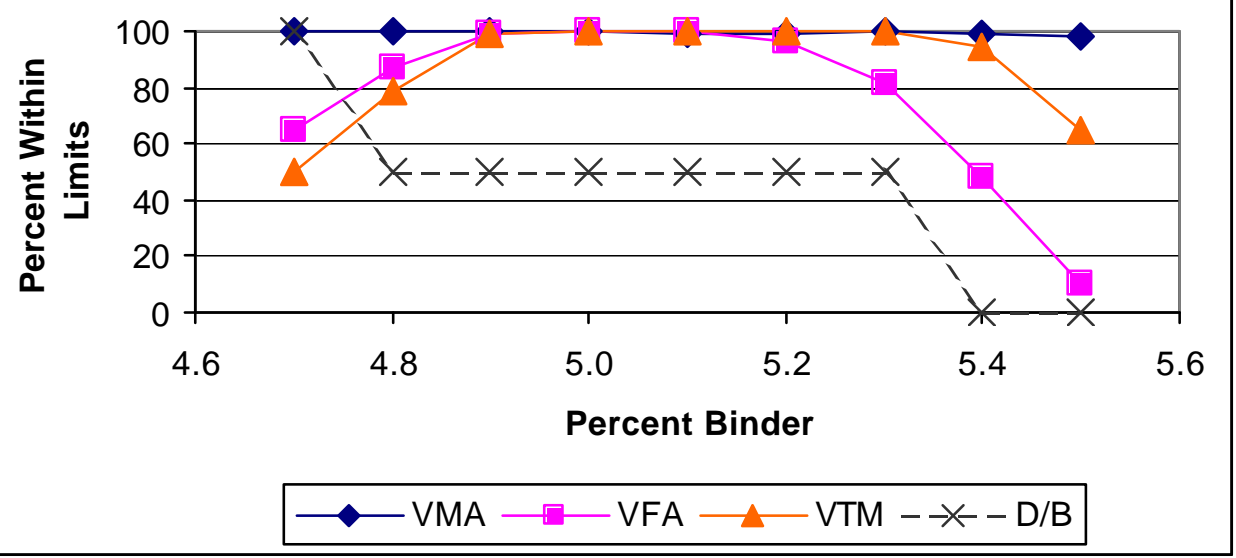

d) Volumetrics for $19 \mathrm{~mm}$ 64-22 Mix

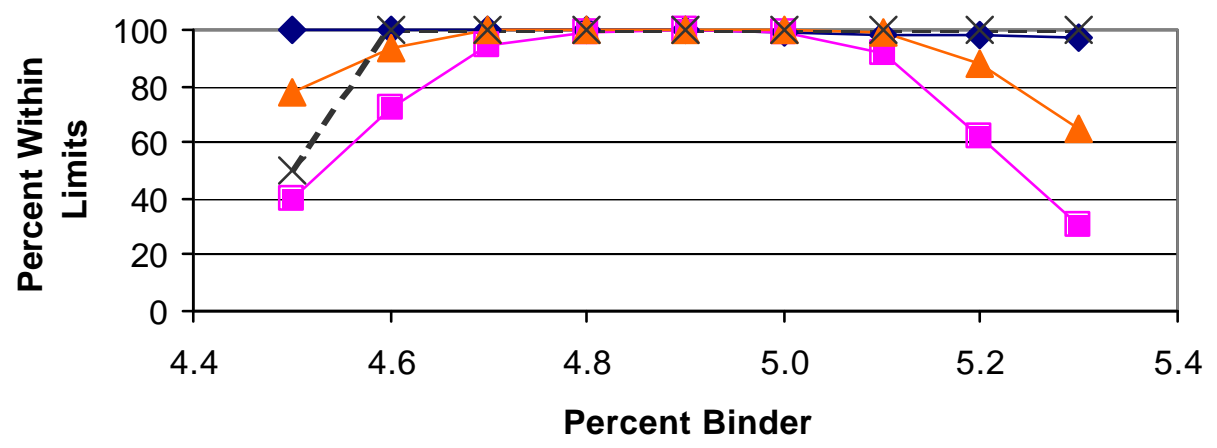

$\multimap-V M A \multimap-V F A \multimap$ VTM $--x--$ D/B

e) Volumetrics for $19 \mathrm{~mm}$ 70-22 Mix

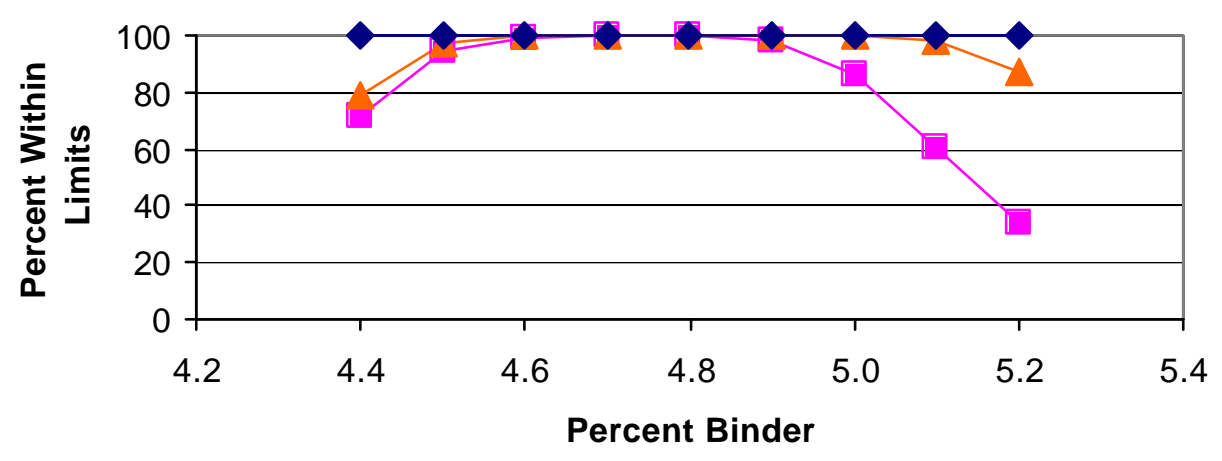

$$
\multimap \text { VMA } \because-\text { VFA } \multimap \text { VTM } \multimap \text { D/B }
$$


Figure 4.1: Continued
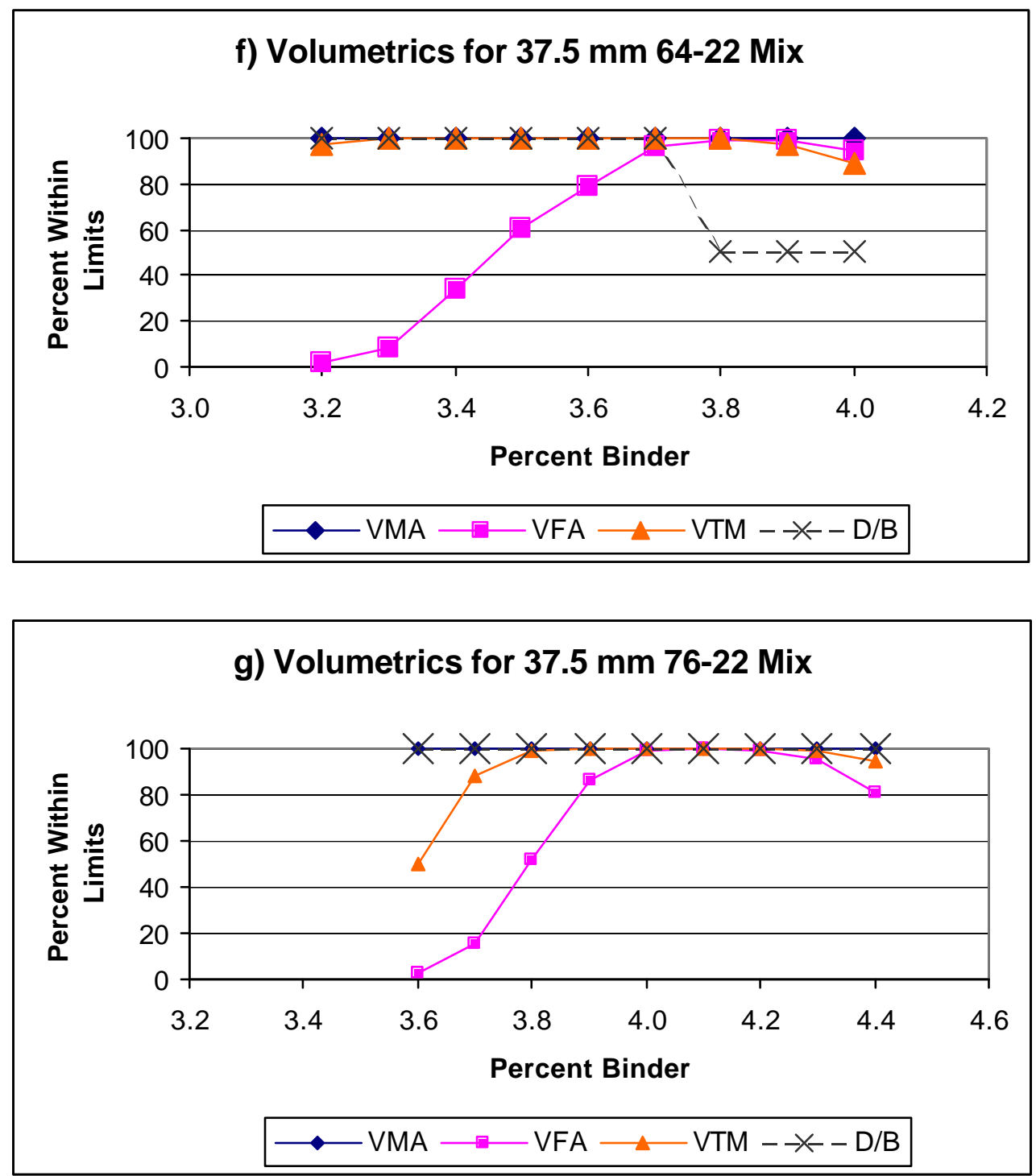


\subsubsection{Quality Assurance Analysis}

The results of the quality assurance analysis are presented in Table 4.6. The statistics used for the development of the quality assurance analysis were based on a 1 in 20 chance that a test result would fail the criteria due to variability associated with sampling and testing. The percent binder results in Table 4.6 demonstrate that, for this parameter, the failure rate is reasonable if there are 10 quality control tests. If there are fewer tests, the percent of tests that fall outside the acceptable range is reduced. This is associated with the inc rease in the multiplier for the range used in Equation 2.1. For fewer tests, the allowable range is increased. For the other quality control parameters, the rate of rejection is much higher than expected. In general, when there are 10 quality control tests the rate of rejection is as high as 20 percent or four times greater than expected. It may be noted that the percent binder is determined directly from the ignition oven test, so the development of criteria for the limits is fairly straightforward. The other parameters, which show a higher rejection rates, are the result of multiple tests and, therefore, the development of criteria is much more difficult. Table 4.6 also shows a considerable difference in the rate of rejection for the $\mathrm{D} / \mathrm{B}$ criteria based on the sample size used to determine the gradation and, hence, the percent of aggregate passing the $0.075 \mathrm{~mm}$ sieve. The rejection rate of $\mathrm{D} / \mathrm{B}$ is much greater when the $\mathrm{P}_{0.075}$ is determined based on a $500 \mathrm{~g}$ sample. 
Table 4.6: Quality Assurance Results

\begin{tabular}{|c|c|c|c|c|c|c|c|}
\hline Mix Type & Binder Type & \multicolumn{6}{|c|}{ Percent Binder (Pb)* } \\
\hline \hline \multicolumn{2}{|c|}{ No. of QC tests } & 10 & 9 & 8 & 7 & 6 & 5 \\
\hline $9.5 \mathrm{~mm}$ & PG 64-22 & 3.8 & 2.3 & 0.7 & 0.1 & 0.0 & 0.1 \\
\hline $9.5 \mathrm{~mm}$ & PG 70-22 & 2.9 & 2.8 & 1.1 & 0.3 & 0.3 & 0.0 \\
\hline $12.5 \mathrm{~mm}$ & PG 76-22 & 2.7 & 2.5 & 1.0 & 0.1 & 0.2 & 0.0 \\
\hline $19 \mathrm{~mm}$ & PG 64-22 & 3.2 & 2.6 & 0.8 & 0.3 & 0.1 & 0.0 \\
\hline $19 \mathrm{~mm}$ & PG 70-22 & 4.1 & 5.0 & 1.5 & 0.8 & 0.1 & 0.0 \\
\hline $37.5 \mathrm{~mm}$ & PG 64-22 & 3.0 & 1.8 & 0.3 & 0.0 & 0.2 & 0.0 \\
\hline $37.5 \mathrm{~mm}$ & PG 76-22 & 1.7 & 2.2 & 0.5 & 0.1 & 0.1 & 0.0 \\
\hline
\end{tabular}

\begin{tabular}{|c|c|c|c|c|c|}
\hline \multicolumn{5}{|c|}{ Voids Filled with Asphalt (VFA)* } \\
\hline \hline 10 & 9 & 8 & 7 & 6 & 5 \\
\hline 18.8 & 16.2 & 14.1 & 10.7 & 6.4 & 3.0 \\
\hline 21.3 & 18.4 & 17.8 & 13.2 & 9.0 & 3.1 \\
\hline 18.6 & 17.6 & 16.1 & 10.5 & 6.9 & 2.4 \\
\hline 20.0 & 18.7 & 13.1 & 9.0 & 5.7 & 2.6 \\
\hline 19.2 & 15.2 & 13.3 & 10.0 & 5.8 & 2.4 \\
\hline 19.1 & 18.3 & 12.4 & 12.2 & 8.2 & 3.2 \\
\hline 18.8 & 17.0 & 16.1 & 10.8 & 6.4 & 2.6 \\
\hline
\end{tabular}

\begin{tabular}{|c|c|c|c|c|c|c|c|}
\cline { 2 - 8 } \multicolumn{2}{c|}{} & \multicolumn{6}{c|}{ Voids in Total Mix (VTM)* } \\
\hline \multicolumn{2}{c|}{ No. of QC tests } & 10 & 9 & 8 & 7 & 6 & 5 \\
\hline $9.5 \mathrm{~mm}$ & PG 64-22 & 18.7 & 16.3 & 15.1 & 10.9 & 7.0 & 2.7 \\
\hline $9.5 \mathrm{~mm}$ & PG 70-22 & 22.4 & 19.7 & 17.4 & 13.0 & 10.1 & 3.1 \\
\hline $12.5 \mathrm{~mm}$ & PG 76-22 & 19.5 & 19.3 & 14.0 & 12.4 & 7.2 & 3.4 \\
\hline $19 \mathrm{~mm}$ & PG 64-22 & 19.5 & 17.9 & 15.9 & 11.6 & 6.3 & 1.6 \\
\hline $19 \mathrm{~mm}$ & PG 70-22 & 18.2 & 17.9 & 13.8 & 9.1 & 6.1 & 1.7 \\
\hline $37.5 \mathrm{~mm}$ & PG 64-22 & 19.6 & 18.2 & 14.2 & 11.7 & 8.4 & 3.5 \\
\hline $37.5 \mathrm{~mm}$ & PG 76-22 & 20.8 & 18.8 & 17.1 & 12.1 & 8.5 & 2.6 \\
\hline
\end{tabular}

\begin{tabular}{|c|c|c|c|c|c|}
\hline \multicolumn{5}{|c|}{ Dust to Binder Ratio (D/B) * } \\
\hline \hline 10 & 9 & 8 & 7 & 6 & 5 \\
\hline 7.9 & 7.7 & 0.6 & 0.7 & 1.3 & 2.0 \\
\hline 8.8 & 10.2 & 0.4 & 1.3 & 1.8 & 1.7 \\
\hline 3.0 & 5.2 & 0.3 & 0.2 & 0.8 & 0.7 \\
\hline 15.3 & 14.3 & 1.8 & 2.5 & 1.9 & 2.8 \\
\hline 13.0 & 15.9 & 1.4 & 1.8 & 2.7 & 3.4 \\
\hline 11.5 & 13.2 & 0.6 & 1.6 & 1.6 & 1.8 \\
\hline 12.9 & 15.2 & 2.0 & 2.0 & 2.1 & 2.3 \\
\hline
\end{tabular}

\begin{tabular}{|c|c|c|c|c|c|c|c|}
\cline { 3 - 7 } \multicolumn{2}{c|}{} & \multicolumn{6}{c|}{ Voids in Mineral Aggregate (VMA)* } \\
\hline \multicolumn{2}{c|}{ No. of QC tests } & 10 & 9 & 8 & 7 & 6 & 5 \\
\hline $9.5 \mathrm{~mm}$ & PG 64-22 & 19.6 & 17.5 & 15.1 & 11.2 & 6.4 & 1.6 \\
\hline $9.5 \mathrm{~mm}$ & PG 70-22 & 16.4 & 17.1 & 14.6 & 9.8 & 4.9 & 2.8 \\
\hline $12.5 \mathrm{~mm}$ & PG 76-22 & 19.3 & 17.4 & 14.7 & 9.8 & 7.1 & 2.6 \\
\hline $19 \mathrm{~mm}$ & PG 64-22 & 19.9 & 16.9 & 16.5 & 11.2 & 7.5 & 2.6 \\
\hline $19 \mathrm{~mm}$ & PG 70-22 & 21.4 & 18.6 & 13.6 & 12.6 & 6.7 & 3.2 \\
\hline $37.5 \mathrm{~mm}$ & PG 64-22 & 20.3 & 20.1 & 12.5 & 9.0 & 5.9 & 1.7 \\
\hline $37.5 \mathrm{~mm}$ & PG 76-22 & 16.8 & 17.2 & 15.3 & 9.9 & 5.1 & 1.6 \\
\hline
\end{tabular}

\begin{tabular}{|c|c|c|c|c|c|}
\hline \multicolumn{7}{|c|}{ Dust to Binder Ratio (D/B) } \\
(500 g samples)* \\
\hline \hline 10 & 9 & 8 & 7 & 6 & 5 \\
\hline 28.8 & 34.9 & 23.1 & 26.0 & 22.7 & 13.5 \\
\hline 31.5 & 35.3 & 27.1 & 23.7 & 22.9 & 12.7 \\
\hline 32.5 & 32.0 & 25.7 & 23.4 & 19.4 & 13.3 \\
\hline 29.1 & 28.3 & 24.6 & 19.8 & 17.8 & 9.6 \\
\hline 29.1 & 29.0 & 24.2 & 22.7 & 18.9 & 8.7 \\
\hline 34.9 & 34.3 & 29.0 & 27.2 & 22.7 & 15.6 \\
\hline 31.4 & 31.8 & 28.1 & 24.1 & 18.6 & 12.8 \\
\hline
\end{tabular}

* Values represent the percent of failures. 


\section{CHAPTER 5}

\section{CONCLUSIONS AND RECOMMENDATIONS}

\subsection{SUMMARY}

Current practice of quality control for Superpave hot mix asphalt by WVDOH has caused concern over the fairness of the specifications. The current specifications focus on volumetric parameters as a means to evaluate the quality of hot mix asphalt concrete.

The research presented herein uses Monte Carlo simulation to determine the probability that a quality control result will fall outside the acceptance limits based due to the variability of the test methods. The quality control parameters used by the WVDOH for Superpave mixes are the percent binder, voids in total mix, voids in mineral aggregate and dust to binder ratio. When Superpave was introduced, voids filled with asphalt was also a quality control parameter, so it was included in the research even though the WVDOH has removed this requirement. Other states may still be using this parameter and may benefit from the results produced during this analysis. The percent binder is the only quality control parameter that is directly measured by testing. All of the other parameters require multiple tests to determine their values. This complicates the determination of the probability distribution function for the QC parameter in a deterministic manner. Hence, the need to use a simulation tool was necessary. Monte Carlo simulation has been used for evaluating the mix design process, but no citations were found in the literature on using this tool to evaluate the QC/QA process.

MCS requires quantification of the probability distribution function for each of the parameters included in the simulated result. AASHTO and ASTM test methods include precision statements, which essentially define the standard deviation of the test method. This implies that the test results are normally distributed. Assuming this is the case, the probability distribution function for each test is defined by a mean and a standard deviation. For this research, mean values for the tests were determined as the target values for the parameter based on WVDOH approved mix designs. The precision statement for each test method was used as the estimate of the standard deviation for a test result. For the quality control parameters, which required multiple test procedures, 
standard volumetric formulas were used to compute the resultant quality control parameter. These functions were programmed into an Excel worksheet for performing the Monte Carlo simulation. For the analysis of the quality control procedures, the @ Risk add-in program for Excel was used to simplify the development of the Monte Carlo simulation. However, for the analysis of the quality assurance procedure it was more expedient to develop a small Visual Basic for Applications program to perform the Monte Carlo simulation.

Using the MCS, the quality control parameters were evaluated for seven different combinations of mix types and binder grades. Each mix was evaluated separately for the five quality control parameters.

\subsection{CONCLUSIONS}

The MCS of the quality control procedure demonstrated that variability in the test methods and subsequent calculation of the quality control parameters does not overly influence the determination of whether or not a mix has acceptable properties. If hot mix asphalt is being produced with an asphalt content near the target value from the mix design, there is less than a two percent chance that the test results will be outside of the specification limits due to the variability in the testing methods. The voids filled with asphalt parameter is an exception to this statement. In one case, there was a 35 percent chance that a mix would fail the VFA criteria due to test method variability. However, if there is a "drift" in the asphalt content by more than two-tenths percent, the potential for rejecting the mix due to voids in the total mix being outside the specification limits increases.

The MCS of the quality assurance process demonstrated it is not as robust as the quality control process. The QC parameters, other than percent binder, can have a 20 percent or greater probability of rejection due to the variability in the test method, especially if the QA result is tested against a range established from 10 QC tests. When a QA test falls outside of the acceptable range, the WVDOH procedure is to investigate the testing to determine if there was a flaw in either the QC or QA test methods or analysis. This is a rather benign consequence and, hence, a high rejection rate may be acceptable. 
In fact a periodic review of testing equipment, techniques and procedures is probably beneficial to the overall quality control and assurance program.

The MCS of the quality control program indicates that the variability associated with the Superpave quality control program is not causing undue errors of either accepting bad mixes nor rejecting acceptable mixes. However, the quality assurance

process may be resulting in more reviews of the testing process than was intended when the procedures were developed.

\subsection{RECOMMENDATIONS}

- Continue with current practices

- Contractor benefits by keeping $\mathrm{P}_{\mathrm{b}}$ plus or minus $2 \%$

- Repeat Hand and Epps research for West Virginia 


\section{REFERENCES}

ASTM Annual Book of ASTM Standards. Volume 4.02. West Conshohocken, PA. (2000)

AASHTO Standard Specifications for Transportation Materials and Methods of Sampling and Testing. Part I and Part II. Washington, D.C. (2000)

Cominsky, R.J. B.M. Killingsworth, R.M. Anderson, and D.A. Anderson, 'Quality Control and Acceptance of Superpave-Designed Hot Mix Asphalt", Report 409, National Cooperative Highway Research Program, Washington D.C. 1998

Darlington, R. and Carlson, P. Behavior Statistics. The Free Press, 1975.

Decker, D.S. "How is Superpave Impacting the Contractor?" 2nd Eurasphalt \& Eurobitume Congress Barcelona 2000. Book I, 172-178. http://www.eecongress.org/2000/pdfbook3/session1/proc0286uk.pdf (11/10/03)

Epperly, R., Letter to the West Virginia Contractors, July 23, 2003

Hand, A. and Epps, A. "Effects of Test Variability on Mixture Volumetrics and Mix Design Verification", Journal of the Association of Asphalt Paving Technologists,Proceedings, Vol. 69, 2000, pp. 635-674, Washington, USA

Hutchinson, S. and Bandalos, D. A Guide to Monte Carlo Simulation Research for Applied Researchers. Journal of Vocational Education Research, 22, 233-245. (1997).

Newcomb, D.E., and Epps, J.A., January/February. "Statistical Specifications for Hot Mix Asphalt: What Do We Need to Know" Hot Mix Asphalt Technology, 54-59. (2001a)

Newcomb, D.E., and Epps, J.A., March/April. "Statistical Specifications for Hot Mix Asphalt: What Do We Need to Know" Hot Mix Asphalt Technology, 37-40. (2001b)

Palisade Corporation. @RISK Manual. (1997). Newfield, NY:

Peterson, J., Probability Analysis of Slope Stability, Master Thesis, West Virginia University, Morgantown, WV 1999

Riegle, J., Development of an Integrated Project Level Pavement Management Model Using Risk Analysis, Ph.D. Dissertation, West Virginia University, Morgantown, WV, 2000

Roberts, F., Kandhal, P., Brown, E., Lee, D., and Kennedy, T. Hot Mix Asphalt Materials, Mixture Design, and Construction. Second Edition, NAPA Research and Education Foundation, 1996.

USDOE, "Introduction to Monte Carlo Methods". U.S. Department of Energy. Computational Science Education Project. http://csep1.phy.ornl.gov/mc/mc.html $(10 / 25 / 03)$ 


\section{TEST METHODS AND MATERIAL PROCEDURES}

\section{$\underline{\text { AASHTO Test Methods }}$}

- $\quad$ AASHTO PP-28

- AASHTO R 9-97: Acceptance Sampling Plans for Highway Construction

- AASHTO T 11-91: Materials Finer Than No. 200 Sieve in Mineral Aggregates by Washing

- AASHTO T 19/T 19M-00: Bulk Density and Voids in Aggregate

- AASHTO T 27-99: Sieve Analysis of Fine and Coarse Aggregates

- $\quad$ AASHTO T 30-98: Mechanical Analysis of Extracted Aggregate

- AASHTO T 84-00: Specific Gravity and Absorption of Fine Aggregate

- AASHTO T 85-96: Specific Gravity and Absorption of Coarse Aggregate

- AASHTO T 164-97: Quantitative Extraction of Bituminous Paving Mixtures

- AASHTO T 166-00: Bulk Specific Gravity of Compacted Asphalt Mixtures Using Saturated Surface-Dry Specimens

- AASHTO T 195: Determining Degree of Particle Coating of BituminousAggregate Mixtures

- AASHTO T 209-99: Theoretical Maximum Specific Gravity and Density of Bituminous Paving Mixtures

- AASHTO T 240-97: Effect of Heat and Air on a Moving Film of Asphalt (Rolling Thin Film Oven)

- $\quad$ AASHTO T 269-97: Percent Air Voids in Compacted Dense and Open Bituminous Paving Mixtures

- AASHTO T304-00: Uncompacted Void Content of Fine Aggregate

- AASHTO T308-99 (METHOD A): Determining the Asphalt Binder Content of Hot-Mix Asphalt by Ignition Method 
- AASHTO T312: Preparing and Determining the Density of Hot-Mix Asphalt Specimens by Means of the Superpave Gyratory Compactor

\section{$\underline{\text { ASTM Test Methods }}$}

- ASTM C 670-96: Preparing Precision and Bias Statements for Test Methods for Construction Materials

- ASTM D5821-95: Determining the Percentage of Fractured Faces in Coarse Aggregate

- ASTM D70-90: Specific Gravity and Density of Semi-Solid Bituminous Materials

\section{WVDOH Material Procedures}

Material Procedures. West Virginia Division of Transportation.

http://www.wvdot.com/10_contractors/10f7_procedures.htm(10/20/03)

- 401.02.29: Guideline for Quality Control and Acceptance Requirements for Superpave Hot-Mix Asphalt

- 401.03.50: Guide for Contractor's Quality Control of Bituminous Concrete

- 700.00.54: Procedure for Evaluating Quality Control Sample Test Results with Verification Sample Test Results 
APPENDIX 1 
Table A-1: Within Laboratory Calculations

\begin{tabular}{|c|c|c|c|c|c|c|c|c|c|c|c|c|c|}
\hline \multicolumn{5}{|l|}{$9.5 \mathrm{~mm}$ mix with PG 64-22 } & \multicolumn{2}{|c|}{ Control Limits } & \multicolumn{2}{|c|}{$\mathrm{Z}$ value } & \multicolumn{2}{|c|}{ Percent Outside } & \multicolumn{2}{|c|}{ |Percent Within Limit* } & \\
\hline Volumetric Parameter & JMF & Mean & Std. Dev. & $\begin{array}{l}\text { Std. Dev. } \\
\text { for Means }\end{array}$ & Lower & Upper & Lower & Upper & Lower & Upper & Lower & Upper & $\begin{array}{l}\text { Total Percent } \\
\text { Within Limit }\end{array}$ \\
\hline Percent Binder & 6.3 & 6.3 & 0.041 & 0.021 & 5.9 & 6.7 & 9.76 & 9.76 & $\overline{0}$ & $\overline{0}$ & 100 & 100 & 100 \\
\hline Voids in Total Mix & 4.0 & 4.0 & 0.518 & 0.259 & 2.8 & 5.2 & 2.32 & 2.32 & 1.02 & 1.02 & 98.98 & 98.98 & 97.96 \\
\hline Voids in Mineral Aggregate & 16.0 & 16.2 & 0.499 & 0.250 & 15.0 & 17.0 & 2.4 & 1.6 & 0.82 & 5.48 & 99.18 & 94.52 & 93.7 \\
\hline Voids Filled with Asphalt & 75.0 & 75.3 & 3.261 & 1.631 & 63.0 & 77.0 & 3.77 & 0.52 & 0.01 & 30.15 & 99.99 & 69.85 & 69.84 \\
\hline Dust to Binder Ratio & 0.7 & 0.8 & 0.008 & 0.004 & 0.6 & 1.2 & 25 & 50 & 0 & 0 & 100 & 100 & 100 \\
\hline Dust to Binder Ratio (500 g sample) & & 0.8 & 0.019 & 0.010 & 0.6 & 1.2 & 10.53 & 21.05 & 0 & 0 & 100 & 100 & 100 \\
\hline
\end{tabular}

\begin{tabular}{|c|c|c|c|c|c|c|c|c|c|c|c|c|c|}
\hline \multicolumn{5}{|l|}{$9.5 \mathrm{~mm}$ mix with PG 70-22 } & \multicolumn{2}{|c|}{ Control Limits } & \multicolumn{2}{|c|}{$\mathrm{Z}$ value } & \multicolumn{2}{|c|}{ Percent Outside } & \multicolumn{2}{|c|}{ Percent Within Limit将 } & \\
\hline Volumetric Parameter & JMF & Mean & Std. Dev. & Std. Dev. & Lower & Upper & Lower & Upper & Lower & Upper & Lower & Upper & Total Percent \\
\hline Percent Binder & 5.7 & 5.7 & 0.040 & 0.020 & 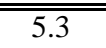 & 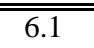 & 10 & 10 & 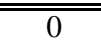 & 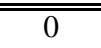 & 100 & 100 & 100 \\
\hline Voids in Total Mix & 4.0 & 4.0 & 0.512 & 0.256 & 2.8 & 5.2 & 2.34 & 2.34 & 0.96 & 0.96 & 99.04 & 99.04 & 98.08 \\
\hline Voids in Mineral Aggregate & 15.5 & 15.2 & 0.479 & 0.240 & 14.5 & 16.5 & 1.46 & 2.71 & 7.21 & 0.34 & 92.79 & 99.66 & 92.45 \\
\hline Voids Filled with Asphalt & 74.0 & 73.5 & 3.483 & 1.742 & 63.0 & 77.0 & 3.01 & 1 & 0.13 & 15.87 & 99.87 & 84.13 & 84 \\
\hline Dust to Binder Ratio & 1.0 & 0.9 & 0.009 & 0.005 & 0.6 & 1.2 & 33.33 & 33.33 & 0 & 0 & 100 & 100 & 100 \\
\hline Dust to Binder Ratio (500 g sample) & & 0.9 & 0.021 & 0.011 & 0.6 & 1.2 & 14.29 & 14.29 & 0 & 0 & 100 & 100 & 100 \\
\hline
\end{tabular}




\begin{tabular}{|c|c|c|c|c|c|c|c|c|c|c|c|c|c|}
\hline \multicolumn{5}{|l|}{$12.5 \mathrm{~mm}$ mix with PG 76-22 } & \multicolumn{2}{|c|}{ Control Limits } & \multicolumn{2}{|c|}{$\mathrm{Z}$ value } & \multicolumn{2}{|c|}{ Percent Outside } & \multicolumn{2}{|c|}{ |Percent Within Limit* } & \\
\hline Volumetric Parameter & JMF & Mean & Std. Dev. & Std. Dev. & Lower & Upper & Lower & Upper & Lower & Upper & Lower & Upper & Total Percent \\
\hline Percent Binder & 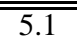 & 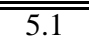 & 0.040 & $\overline{0.020}$ & 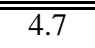 & 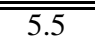 & 10 & 10 & 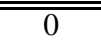 & $\overline{00}$ & 100 & 100 & 100 \\
\hline Voids in Total Mix & 4.0 & 4.0 & 0.504 & 0.252 & 2.8 & 5.2 & 2.38 & 2.38 & 0.87 & 0.87 & 99.13 & 99.13 & 98.26 \\
\hline Voids in Mineral Aggregate & 14.5 & 14.1 & 0.462 & 0.231 & 13.5 & 15.5 & 1.3 & 3.03 & 9.68 & 0.12 & 90.32 & 99.88 & 90.2 \\
\hline Voids Filled with Asphalt & 70.0 & 71.8 & 3.688 & 1.844 & 63.0 & 77.0 & 2.39 & $\overline{1.41}$ & 0.84 & 7.93 & 99.16 & 92.07 & 91.23 \\
\hline Dust to Binder Ratio & 1.0 & 0.8 & 0.010 & 0.005 & 0.8 & 1.6 & 0 & 80 & 50 & 0 & 50 & 100 & 50 \\
\hline Dust to Binder Ratio (500 g sample) & & 0.8 & 0.023 & 0.012 & $\overline{0.8}$ & 1.6 & 0 & 34.78 & 50 & 0 & 50 & 100 & 50 \\
\hline
\end{tabular}

\begin{tabular}{|c|c|c|c|c|c|c|c|c|c|c|c|c|c|}
\hline \multicolumn{5}{|l|}{19 mm mix with PG 64-22 } & \multicolumn{2}{|c|}{ Control Limits } & \multicolumn{2}{|c|}{$\mathrm{Z}$ value } & \multicolumn{2}{|c|}{ Percent Outside } & \multicolumn{2}{|c|}{ |Percent Within Limit* } & \\
\hline Volumetric Parameter & JMF & Mean & Std. Dev. & Std. Dev. & Lower & Upper & Lower & Upper & Lower & Upper & Lower & Upper & Total Percent \\
\hline Percent Binder & 4.9 & 4.9 & 0.040 & 0.020 & 4.5 & 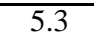 & 10 & 10 & 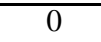 & 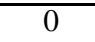 & 100 & 100 & 100 \\
\hline Voids in Total Mix & 4.0 & 4.0 & 0.513 & 0.257 & 2.8 & 5.2 & 2.34 & 2.34 & 0.96 & 0.96 & 99.04 & 99.04 & 98.08 \\
\hline Voids in Mineral Aggregate & 13.7 & 13.5 & 0.495 & 0.248 & 12.7 & 14.7 & 1.62 & 2.42 & 5.26 & 0.78 & 94.74 & 99.22 & 93.96 \\
\hline Voids Filled with Asphalt & 71.0 & 70.2 & 3.992 & 1.996 & 63.0 & 77.0 & 1.8 & 1.7 & 3.59 & 4.46 & 96.41 & 95.54 & 91.95 \\
\hline Dust to Binder Ratio & 1.3 & 1.1 & 0.009 & 0.005 & 0.6 & 1.2 & 55.56 & 11.11 & 0 & 0 & 100 & 100 & 100 \\
\hline Dust to Binder Ratio (500 g sample) & & 1.1 & 0.025 & 0.013 & 0.6 & 1.2 & 20 & 4 & 0 & 0 & 100 & 100 & 100 \\
\hline
\end{tabular}




\begin{tabular}{|c|c|c|c|c|c|c|c|c|c|c|c|c|c|}
\hline \multicolumn{5}{|l|}{$19 \mathrm{~mm}$ mix with PG 70-22 } & \multicolumn{2}{|c|}{ Control Limits } & \multicolumn{2}{|c|}{$\mathrm{Z}$ value } & \multicolumn{2}{|c|}{ Percent Outside } & \multicolumn{2}{|c|}{ |Percent Within Limit* } & \\
\hline Volumetric Parameter & JMF & Mean & Std. Dev. & Std. Dev. & Lower & Upper & Lower & Upper & Lower & Upper & Lower & Upper & Total Percent \\
\hline Percent Binder & 4.8 & 4.8 & 0.040 & 0.020 & 4.4 & 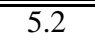 & 10 & 10 & 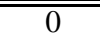 & 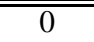 & 100 & 100 & 100 \\
\hline Voids in Total Mix & 4.0 & 4.0 & 0.526 & 0.263 & 2.8 & 5.2 & 2.28 & 2.28 & 1.13 & 1.13 & 98.87 & 98.87 & 97.74 \\
\hline Voids in Mineral Aggregate & 14.0 & 13.9 & 0.483 & 0.242 & 13.0 & 15.0 & 1.86 & 2.28 & 3.14 & 1.13 & 96.86 & 98.87 & 95.73 \\
\hline Voids Filled with Asphalt & 71.0 & 71.3 & 3.946 & 1.973 & 63.0 & 77.0 & 2.1 & 1.44 & 1.79 & 7.49 & 98.21 & 92.51 & 90.72 \\
\hline Dust to Binder Ratio & 0.8 & 0.8 & 0.008 & 0.004 & 0.6 & 1.2 & 25 & 50 & 0 & 0 & 100 & 100 & 100 \\
\hline Dust to Binder Ratio (500 g sample) & & 0.8 & 0.025 & 0.013 & 0.6 & 1.2 & 8 & 16 & 0 & 0 & 100 & 100 & 100 \\
\hline
\end{tabular}

\begin{tabular}{|c|c|c|c|c|c|c|c|c|c|c|c|c|c|}
\hline \multicolumn{5}{|l|}{$\underline{37.5 \mathrm{~mm} \text { mix with PG 64-22 }}$} & \multicolumn{2}{|c|}{ Control Limits } & \multicolumn{2}{|c|}{$\mathrm{Z}$ value } & \multicolumn{2}{|c|}{ Percent Outside } & \multicolumn{2}{|c|}{ Percent Within Limit将 } & \\
\hline Volumetric Parameter & JMF & Mean & Std. Dev. & Std. Dev. & Lower & Upper & Lower & Upper & Lower & Upper & Lower & Upper & Total Percent \\
\hline Percent Binder & 3.6 & 3.6 & 0.046 & 0.023 & 3.2 & 4.0 & 8.7 & 8.7 & 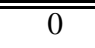 & 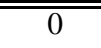 & 100 & 100 & 100 \\
\hline Voids in Total Mix & 4.0 & 4.0 & 0.508 & 0.254 & 2.8 & 5.2 & 2.36 & 2.36 & 0.91 & 0.91 & 99.09 & 99.09 & 98.18 \\
\hline Voids in Mineral Aggregate & 11.7 & 11.7 & 0.477 & 0.239 & 10.7 & 12.7 & 2.1 & 2.1 & 1.79 & 1.79 & 98.21 & 98.21 & 96.42 \\
\hline Voids Filled with Asphalt & 66.0 & 65.8 & 4.584 & 2.292 & 64.0 & 77.0 & 0.39 & 2.44 & 34.83 & 0.73 & 65.17 & 99.27 & 64.44 \\
\hline Dust to Binder Ratio & 1.0 & 0.7 & 0.009 & 0.005 & 0.6 & 1.2 & 11.11 & 55.56 & 0 & 0 & 100 & 100 & 100 \\
\hline Dust to Binder Ratio (500 g sample) & & 0.7 & 0.031 & 0.016 & 0.6 & 1.2 & 3.23 & 16.13 & 0.06 & 0 & 99.94 & 100 & 99.94 \\
\hline
\end{tabular}




\begin{tabular}{|c|c|c|c|c|c|c|c|c|c|c|c|c|c|}
\hline \multicolumn{5}{|l|}{$37.5 \mathrm{~mm}$ mix with PG 76-22 } & \multicolumn{2}{|c|}{ Control Limits } & \multicolumn{2}{|c|}{$\mathrm{Z}$ value } & \multicolumn{2}{|c|}{ Percent Outside } & \multicolumn{2}{|c|}{ |Percent Within Limit* } & \\
\hline Volumetric Parameter & JMF & Mean & Std. Dev. & Std. Dev. & Lower & Upper & Lower & Upper & Lower & Upper & Lower & Upper & Total Percent \\
\hline Percent Binder & 4.0 & 4.0 & 0.041 & 0.021 & 3.6 & 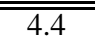 & 9.76 & 9.76 & 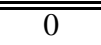 & $\overline{00}$ & 100 & 100 & 100 \\
\hline Voids in Total Mix & 4.0 & 4.0 & 0.500 & 0.250 & 2.8 & 5.2 & 2.4 & 2.4 & 0.82 & 0.82 & 99.18 & 99.18 & 98.36 \\
\hline Voids in Mineral Aggregate & 13.0 & 12.7 & 0.470 & 0.235 & 12.0 & 14.0 & 1.49 & 2.77 & 6.81 & 0.28 & 93.19 & 99.72 & 92.91 \\
\hline Voids Filled with Asphalt & 68.0 & 68.6 & 4.144 & 2.072 & 64.0 & 77.0 & 1.11 & 2.03 & 13.35 & 2.12 & 86.65 & 97.88 & 84.53 \\
\hline Dust to Binder Ratio & 1.0 & 1.0 & 0.010 & 0.005 & 0.8 & 1.6 & 20 & 60 & 0 & 0 & 100 & 100 & 100 \\
\hline Dust to Binder Ratio (500 g sample) & & $\overline{1.0}$ & 0.030 & 0.015 & $\overline{0.8}$ & 1.6 & 6.67 & 20 & 0 & 0 & 100 & 100 & 100 \\
\hline
\end{tabular}




\section{APPENDIX 2}

Visual Basic Program Used for Quality Assurance

Sub qa()

' qa Macro

' Macro recorded 12/21/2004 by ZANIEWSKI

' Keyboard Shortcut: Ctrl+s

Dim i As Integer, $\mathrm{j}$ As Integer, $\mathrm{k}$ As Integer, $\mathrm{m}$ As Integer

Dim itrno As Integer, nomix As Integer, nmi As Integer

Dim nopar As Integer

' iterate for number of parameters

For nopar $=0$ To 5

Cells $(1,1)=$ nopar

$\mathrm{c}=0$

' iterate for the number of mixes

nomix $=7$

For nmi $=0$ To nomix -1

$\operatorname{Cells}(2,2)=n m i$

itrno $=\operatorname{Cells}(2,5)$

Cells $(2,6)=\operatorname{Cells}(22+$ nmi $* 2,5+$ nopar $)$

$\operatorname{Cells}(3,6)=\operatorname{Cells}\left(23+\mathrm{nmi}^{*} 2,5+\right.$ nopar $)$

$\operatorname{Cells}(2,7)=\operatorname{Cells}\left(41+\mathrm{nmi}^{*} 2,5+\right.$ nopar $)$

Cells $(3,7)=\operatorname{Cells}(42+$ nmi $* 2,5+$ nopar $)$

' iterate on number of qa samples

For $\mathrm{k}=2$ To 7

$\mathrm{m}=0$

$\mathrm{j}=\operatorname{Cells}(\mathrm{k}, 11)$

'Repeat iterations counter

For i = 1 To itrno

Cells $(1,2)=\mathrm{i}$ 
Range(Cells(6, 2), Cells(15, 2)).Select

Selection.Copy

Range("g6").Select

Selection.PasteSpecial Paste:=xlValues, Operation:=xlNone, SkipBlanks:=

False, Transpose:=False

Range(Cells(6, 4), Cells $(6+j-1,4))$.Select

Selection.Copy

Range("E6").Select

Selection.PasteSpecial Paste:=xlValues, Operation:=xlNone, SkipBlanks:=

False, Transpose:=False

Range(Cells $(6,6)$, Cells $(6+j-1,6))$.Select

Selection.Copy

Range("g6").Select

Selection.PasteSpecial Paste:=xlValues, Operation:=xlNone, SkipBlanks:=

False, Transpose:=False

high $=\operatorname{Cells}(18,4)+\operatorname{Cells}(18,8) * \operatorname{Cells}(\mathrm{k}, 12)$

low $=\operatorname{Cells}(18,4)-\operatorname{Cells}(18,8) * \operatorname{Cells}(\mathrm{k}, 12)$

$\operatorname{Cells}(2,1)=\mathrm{k}$

$\operatorname{Cells}(3,1)=\operatorname{Cells}(\mathrm{k}, 12)$

$\mathrm{c}=0$

If Cells $(18,11)>$ high Then

$\mathrm{c}=1$

Else

If Cells $(18,11)<$ low Then

$\mathrm{c}=1$

Else: $\mathrm{c}=0$

End If

End If

Cells $(8,1)=\mathrm{c}$

$\operatorname{Cells}(4,1)=$ high 
$\operatorname{Cells}(5,1)=$ low

Cells $(6,1)=\operatorname{Cells}(18,11)$

$\mathrm{m}=\mathrm{m}+\mathrm{c}$

$\operatorname{Cells}(7,1)=m$

Next $\mathrm{i}$

$\operatorname{Cells}(22+\mathrm{nmi} * 2,13+\mathrm{k}-2+\operatorname{nopar} * 6)=\mathrm{m}$

Cells $(1,13)=\mathrm{i}-1$

Next k

Next nmi

Next nopar

End Sub 